\title{
Synthesis and Processing of Biodegradable and Bio-Based Polymers by Microwave Irradiation
}

\author{
Guido Giachi, Marco Frediani, Luca Rosi and Piero Frediani \\ University of Florence \\ Italy
}

\section{Introduction}

Biodegradable polymers, as well as polymers produced from renewable feedstocks, are attracting increasing interests as possible substitutes for conventional plastics: a higher energy efficiency in synthesis and processing steps must be continuously pursued in order to maximize the intrinsic environmental benefits brought by this class of materials. Microwave assisted organic synthesis (MAOS) is nowadays a major topic in green chemistry and a great (yet rising) number of papers can already be found that report striking advantages over conventional thermal heating. Nonetheless microwave (MW) energy sources are recently being chosen also for several polymerization reactions. Indeed, reduced heating times and superior homogeneity provided by MW reactors may play a central role in optimizing production processes, with a dramatic improvement in the environmental performance. In the introduction of this chapter we're briefly recalling some theoretical principles of microwave-matter interaction; several experimental setups are then examined and, eventually, thermal and non-thermal specific microwave effects are described and commented. The following paragraph is dedicated to a comprehensive survey of synthesis examples found in scientific literature and categorized by polymerization technique, in which particular relevance is given to products of increasing commercial importance like poly(e-caprolactone) (PCL) and poly(lactic acid) (PLA). A third part of the chapter deals with the employment of microwave heating for chemical modification and processing of polymers; the last paragraph summarizes advantages and drawbacks of microwave assisted polymer chemistry, stressing the energy efficiency topic and drawing conclusions.

\subsection{Theoretical principles of microwave irradiation}

Microwaves are electromagnetic radiations characterized by frequencies that extend from $0.3 \mathrm{GHz}$ (corresponding to an energy of $1.2 \times 10^{-6} \mathrm{eV}$ ) to $30 \mathrm{GHz}\left(1.2 \times 10^{-3} \mathrm{eV}\right.$ ), covering the portion of the spectrum between the less energetic Radio waves and the more energetic Infrared waves. Due to an intensive employment by the information and telecommunication technologies, only few frequencies among the whole microwave band are actually available for scientific, industrial and household heating applications: in order to avoid any interference, the vast majority of devices operates at $2.45 \mathrm{GHz}\left(1.0 \times 10^{-5} \mathrm{eV}\right)$. Comparing the latter value to the energy associated with some common covalent bonds ( $\mathrm{C}-\mathrm{C}$ single bond: 
$3.61 \mathrm{eV} ; \mathrm{C}=\mathrm{C}$ double bond: $6.35 \mathrm{eV}$ ) or even with a weaker interaction like hydrogen bond $(0.04-0.44 \mathrm{eV})$ it is clear that microwaves do not posses enough energy to induce a chemical reaction by breaking any of these. Very often, indeed, the impressive shortening of reaction times, reported by the authors cited in the following paragraphs, is ascribed to peculiarities in the heating process like homogeneity, inverted temperature gradient (i.e. vial walls are colder than reactants in the bulk) and extremely fast temperature increase. The interaction between microwaves and the electric dipoles of irradiated reactants or solvent molecules is what underlies "dielectric heating". Since the order of magnitude of molecular rotational frequencies is lower, but quite close to microwave frequencies, the tendency to align with the oscillating electromagnetic field produces an immediate and simultaneous motion that can't indefinitely follow the oscillating field and eventually results in thermalization. Kinetic energy is transformed into heat via phenomena (i.e. phase shifts and dielectric losses deriving from molecular friction) whose mechanism depends on both molecular mass (more correctly on rotational moment of inertia) and dielectric coefficient " $\varepsilon$ " of each component of the irradiated reaction mixture. Dielectric coefficient (or complex permittivity) consists of a real component and of an imaginary component $\left(\varepsilon=\varepsilon^{\prime}+\mathrm{i} \varepsilon^{\prime \prime}\right)$ : widely adopted parameters to describe the efficiency of radiation-to-heat conversion are the "loss factor" $(\varepsilon$ ") and the "dissipation factor", indicated with " $\tan (\delta)$ " or " $\mathrm{D}$ " and defined as:

$$
\tan (\delta)=\mathrm{D}=\varepsilon^{\prime \prime} / \varepsilon^{\prime}
$$

Polar solvents and reactants normally possess high values of $\tan (\delta)$, indicating strong microwave absorption; on the other hand low values shown by most non-polar substances indicate transparency and inefficient energy transfer (Fig. 1).

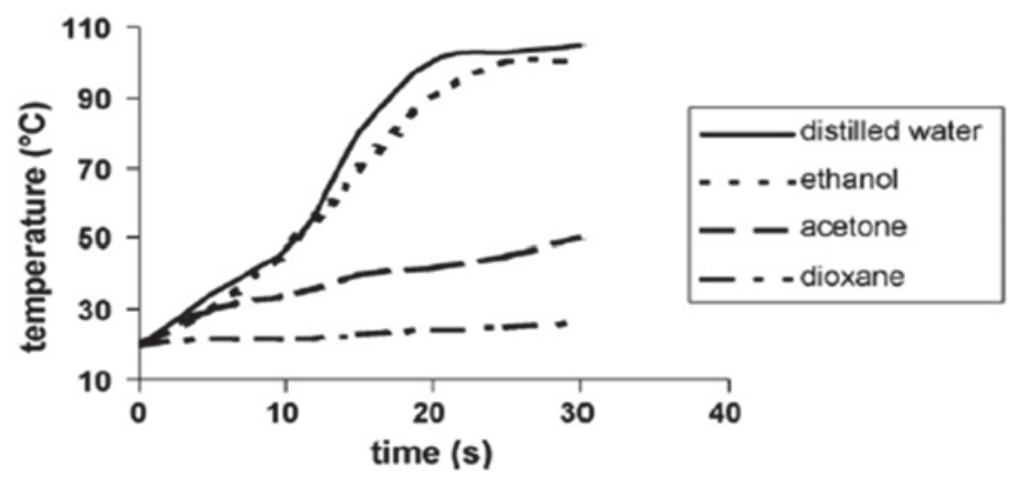

Fig. 1. Microwave heating curves of different solvents in a multimodal cavity (power $=150 \mathrm{~W}$ ) (from C. Leonelli, T.J. Mason, Microwave and Ultrasonic Processing: Now a Realistic Option for Industry, Chemical Engineering and Processing, 2010, 49, 885-90. Copyright Elsevier Ltd. Reproduced with permission).

Even if, commonly, homogeneous heating represents a topic feature of microwave devices it should be noted that highly dielectric materials rapidly diminish the incident radiation intensity, hence recourse to large volumes may cause shielding effects and colder matter at the core. This is the reason why "penetration depth", defined as the point where only $37 \%$ $(1 / \mathrm{e})$ of the incident MW radiation is still present and calculated as the reciprocal of loss 
factor, turns out to be another useful parameter in the characterization of an experiment. Besides absorption and transmission, a third phenomenon can take place: radiation can be reflected by the surface of a body (highly conducting metals are important examples). This eventuality should generally be avoided in setting up a reaction since, while only negligible heating is generated in the reflecting material, microwave constructive interferences may arise elsewhere amid the irradiated matter and cause uneven temperature profiles and "hot spots" on account of local super-heating effects.

\subsection{Microwave heating setups}

Despite papers display sometimes poor technical detail, in microwave assisted synthesis (much more than in conventional chemistry) the choice of the experimental apparatus with its engineering specifications is a matter of chief importance. Reproducibility strongly depends on how accurately actual reaction parameters correspond to the user's setup. Being able to properly tune and monitor the most important variables gives reproducible results that can be fruitfully compared with literature. Unquestionably huge improvements have been achieved in this regard during the last decades: with microwave assisted synthesis gaining more and more attention through the years, several dedicated reactors were commercialized. Nowadays these devices have replaced former domestic MW ovens in many laboratories, delivering new standards in terms of safety, efficacy and parameter regulation. Reactors are frequently subdivided in multi- and mono-modal depending on the way in which microwaves are directed from the magnetron to the sample. Multimodal devices generate a fairly homogeneous electromagnetic field distributing radiations towards different directions through a large cavity in which interference with reflected waves averages field intensity; monomodal devices, on the other hand, feature precisely calibrated waveguides in which radiation is reflected in phase to generate standing waves with a maximum placed at the sample compartment position. Domestic MW ovens are examples of multimodal instruments as well as some high-capacity scientific device, while monomodal applicators are found exclusively among dedicated scientific equipment. Some authors (Nuchter et al., 2004) point out that the aforementioned distinction holds true only until the reaction mixture is placed into the cavity, perturbing the emitted field and turning monomodal reactors into (partly) multimodal ones: a more useful classification should be based, in their view, on radiation intensity or power density. Nonetheless it is generally agreed that monomodal reactors are best suited for small loads (note that, for this class, viable volumes are limited by the dimension of the wavelength itself) since allow to minimize the occurrence of hot spots, a detrimental phenomenon that disturbs reactions in multimodal devices when uneven temperature profiles are not averaged out by a large amount of absorbing matter. This is the reason why it is often recommended (Bogdal et al., 2003) to fill multimodal cavities with samples occupying more than $50 \%$ of the available volume. When large volumes and reliable field homogeneities are required, applicators with radiant geometries may also be profitably employed: the possibility to place antennas in the cavity makes the field much less subject to perturbation by the load (Leonelli \& Mason, 2010). It is worth noting that a central technical feature for synthetic purpose, generally offered by a professional apparatus, is the capability of emitting continuous (i.e. unpulsed) radiation, so that the reaction mixture is heated at a userassigned power level that is constant with time. Inexpensive domestic ovens operate irradiating at their maximum power in a pulsed profile, with the on/off time ratio depending on the chosen power level: this means being able to tune average MW intensity in the whole irradiation period, but obviously exposes to the risk of momentary overheating. Temperature 
control represents a critical engineering point: some authors (F. Liu et al., 2010; Sharma \& Mishra, 2010) still choose to perform the measure immediately after microwave exposure (even a conventional thermometer may be used in this case), however a real-time monitoring is usually favored, nowadays, in order to operate a more accurate control. Three configurations are adopted in the vast majority of the reported examples: at a laboratory scale (industrial application is dampened by their cost and fragility) the preferred and most affordable probes seem to be fiber-optic thermometers inserted in the reaction mixture using transparent tubes. The operative range is $0-300{ }^{\circ} \mathrm{C}$ and some authors report that after few hours at $250{ }^{\circ} \mathrm{C}$ permanent deterioration is already observable (Nuchter et al., 2004); nonetheless high temperature measurement (up to approx. $2000^{\circ} \mathrm{C}$ ) can be performed using sapphire based fiber-optic thermometers. Optical (IR) pyrometers represent a universally viable solution (widespread in commercial technical devices as well as utilizable for large scale industrial reactors) and offer a much wider temperature range $\left(-40{ }^{\circ} \mathrm{C}\right.$ to $\left.1000{ }^{\circ} \mathrm{C}\right)$, but necessarily measure the temperature at the vial wall, which means they invariably underestimate the value. Shielded thermocouples are the cheapest option, can withstand temperatures up to $300{ }^{\circ} \mathrm{C}$ but are quite bulky and require lossy (polar) solvents to avoid excessive MW absorption by their metallic shields which would result in overheating effects and biased measurement. The choice of the proper solvent for a MW assisted reaction must take into account its dielectric coefficient $(\varepsilon)$ and it is worth reminding that in most cases dielectric constants $\left(\varepsilon^{\prime}\right)$ significantly decrease with temperature (Fig. 2): an example is pressurized water at $300{ }^{\circ} \mathrm{C}$ showing a value of 20 which is very close to that of acetone at room temperature (Strauss \& Trainor, 1995).

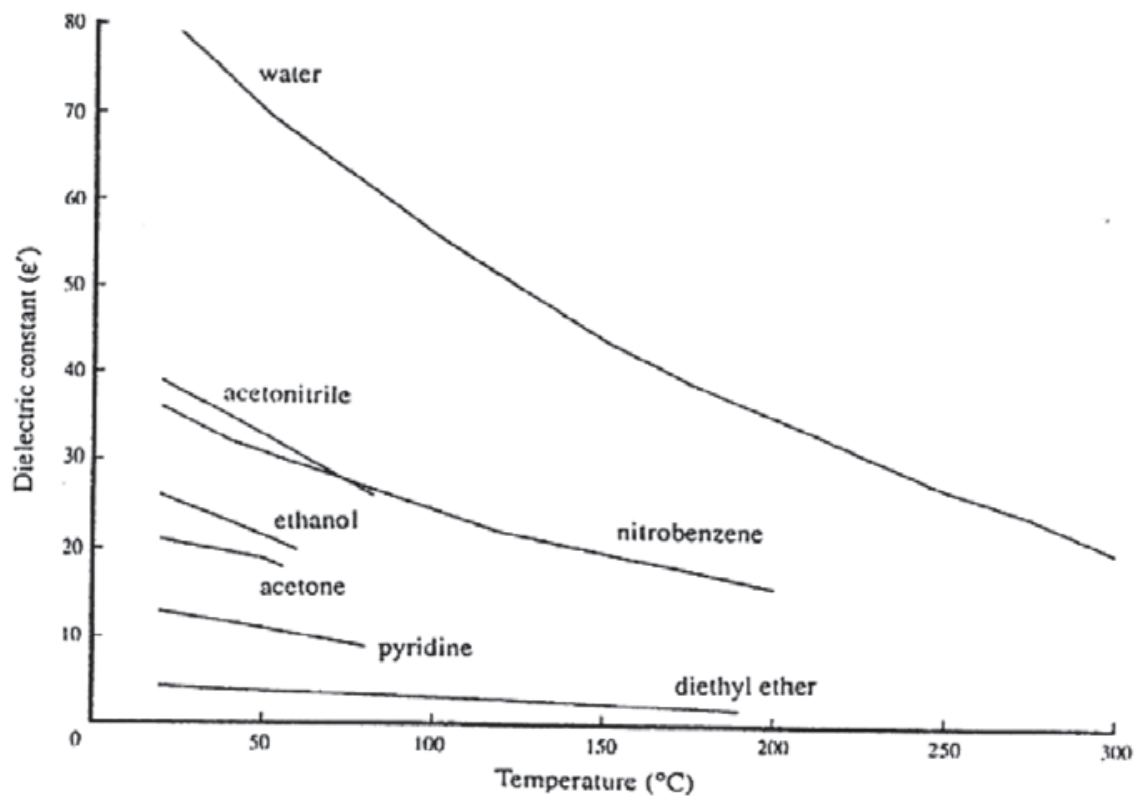

Fig. 2. Dielectric constants vs. temperature for different solvents (from Dean, J. A. Ed.; Lange's Handbook of Chemistry, 13 ${ }^{\text {th }}$ ed.; McGraw-Hill, New York, 1985; p.99, ISBN: 0070161925. Copyright McGrawHill Education. Reproduced with permission). 
Non polar solvents may be employed improving their heating efficiency by small additions (few percents in weight) of miscible liquids with high loss factors or even salts, preferably with a sufficient solubility in order to assure homogeneous conditions (Lidström et al., 2001). A similar approach underlies the diffuse exploitation as heating elements of highly MW absorbing solids, like silicon carbide (Kremsner \& Kappe, 2006) (Fig. 3), carbon black (F. Liu et al., 2010) or silica particles (P. Liu \& Su, 2005). Microwave assisted reactions may also be conducted in environmentally friendly water-miscible ionic liquids which are characterized by high dielectric constants and offer the possibility of isolating hydrophobic products by the addition of water to the homogeneous solution (Guerrero-Sanchez et al., 2007).

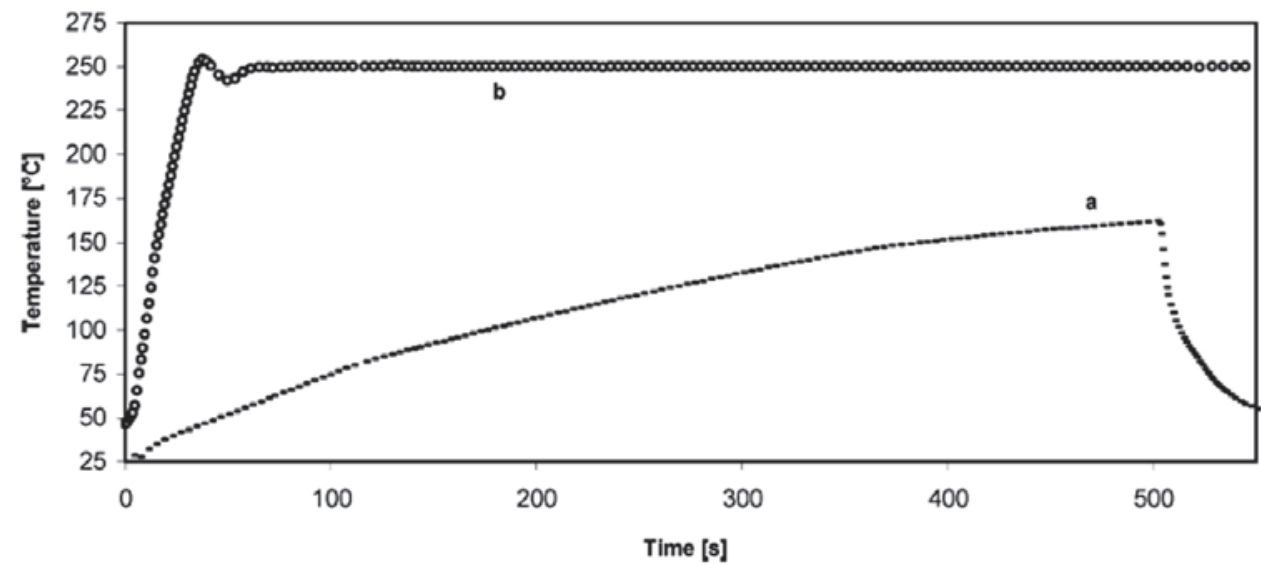

Fig. 3. Microwave heating curves for a $0.2 \mathrm{M}$ solution of allyl phenyl ether in toluene: a) no heating element; b) with $\mathrm{SiC}$ as heating element (from J. M. Kremsner, C. O. Kappe, Silicon Carbide Passive Heating Elements in Microwave-Assisted Organic Synthesis, J. Org. Chem., 2006, 71, 4651-4658. Copyright American Chemical Society (ACS). Reproduced with permission).

When possible, the solvent-free option should always be favored on the basis of the green chemistry principles: the bulk ring opening polymerization of lactide to yield poly(lactic acid) is a notable case (Frediani et al., 2010). Early experiments were often performed in open vessels, at a temperature below the boiling point of high-boiling solvents (e.g. DMSO or DMF). This simplest configuration may as well comply with solvent-free reactions not requesting modified atmosphere, in which at least one of the reactants is a high-boiling liquid or a lowmelting solid capable of efficient microwave absorption. Even if open vessels were tentatively adopted with more volatile solvents like toluene, increasing fire hazards brought by this choice should be seriously considered. Pressurized vials allow to use solvents at a temperature above their boiling point, considerably increasing reaction rates, though it should be noted that gastight sealed caps might cause explosions: technical devices usually feature dedicated vials equipped with proper septa capable of withstanding pressures up to a determinate value. Examples of customized reflux systems are frequently found in literature (Waugh \& Parkin, 2010; Zhu et al., 2003): this particular setup proved to be safe and easy to scale-up, on the other hand it precludes overheating limiting the advantages of microwave irradiation over conventional heating. It is eventually worth mentioning that industrial-scale MW generators 
can be engineered to work efficiently under conditions from full vacuum to $1.03 \mathrm{MPa}$ and from $30{ }^{\circ} \mathrm{C}$ to $200{ }^{\circ} \mathrm{C}$ (Leonelli et al., 2007). Microwave assisted synthesis is gaining increasing appeal for industrial applications, therefore the possibility of scaling-up reactions becomes a pivoting issue. One major limitation that prevents the load of large volumes at one time is the penetration depth of microwaves through lossy solvents or reactants: as already stated, the shielding of radiation by the peripheral matter produces inefficient heating at the core. Besides, heating large quantities of liquids in sealed vessels augments explosion hazard and obligate to employ thick, robust walls that must be MW transparent at the same time. It is eventually worth noting that massive quantities contained in thick vials are very difficult to cool rapidly and evenly with water or pressurized air. This critical points may be circumvented by loading high volumes in smaller, separated vials in parallel (a tedious configuration for large scale) or more efficiently by switching to a continuous flow reactor equipped with a relatively thin reaction tube through which reactants and solvents move in a necessarily homogeneous solution (Moseley \& Woodman, 2008; Glasnow \& Kappe, 2007). Open vials were successfully chosen for the irradiation of volumes up to $1000 \mathrm{~mL}$ (Deetlefs \& Seddon, 2003) though it should be pointed out that MW penetration depth and the boiling point of the mixture limit the feasibility of such a layout. When only high-boiling substances are employed, solvent free reactions may also be performed with vials sealed under vacuum. As an example, the bulk ring opening polymerization of Caprolactone was recently performed loading five $1.8 \mathrm{~L}$ customized glass tubes with about $800 \mathrm{~g}$ of monomer each and irradiating simultaneously into a large multimodal microwave heater (Xu et al., 2010).

\section{3 "Thermal" and "non-thermal" specific microwave effects}

Since the early works, the astonishing increase in microwave-assisted reaction rates observed by many authors posed a number of questions about the rational origins of this phenomenon. A large variety of differences have been described between experiments conducted under conventional or microwave conditions: normally these findings are explained on the basis of rational hypotheses, but the lack of a rigorous and generally adopted terminology sometimes generates ambiguity when it comes to surveying the related literature. One frequent distinction is made between "thermal" and "non thermal" effects, sometimes called "specific microwave" effects. Precisely, also the "thermal" effects are microwave-specific: despite being based on heating phenomena they cannot be obtained by conventional oil baths. Dealing with variations in reaction kinetics, former works (Perreux \& Loupy, 2001) sensibly suggested to refer to the Arrhenius equation:

$$
\mathrm{k}=\mathrm{A} \exp \left(-\Delta \mathrm{G}^{\neq} / \mathrm{RT}\right)
$$

In the equation three variables may be influenced by the use of microwaves as energy source, hence the rate $(\mathrm{k})$ can be enhanced by three contributions: higher pre-exponential factor (A) due to increased collision efficiency; lower activation energy ( $\Delta \mathrm{G} \neq=\Delta \mathrm{H}^{\neq}-\mathrm{T} \Delta \mathrm{S} \neq$ ) due to stabilized polar transition states and eventually a higher actual temperature. The latter can obviously be listed as a "thermal" effect, and comprises the phenomena of local superheating and hotspots, inverted temperature gradient (i.e. wall effect), selective heating and similar. The variations of $A$ and $\Delta G \neq$, on the other hand, may stem from the peculiar mechanism of interaction between matter and electromagnetic field, and therefore could be catalogued as "non thermal" effects. It should be pointed out that this approach holds also for the quite frequent cases of altered or enhanced reaction selectivities: since thermodynamic parameters do not depend upon the energy source, selectivity could be 
identified, here, as a kinetic competition between two or more reaction pathways, keeping in mind that different molecules may absorb microwaves with a different efficiency. This fairly rigorous paradigm is sometimes not applied in the interpretation of real life experiments since relating the observed phenomena to the terms of the equation is not always straightforward. Some authors, indeed, simply compare the real temperatures monitored during conventional and microwave heating procedures and try to estimate whether thermal differences are important enough to justify the discrepancies in their results (Jing et al., 2006). While the occurrence of "non thermal" effects is sometimes claimed and sometimes ruled out, remaining a controversial topic, the factual relevance of "thermal" microwave effects is nowadays widely recognized (though an exhaustive rationalization of their occurrence is still to come). Descriptions of these phenomena are occasionally found and highlighted among the papers surveyed in the following paragraphs.

\section{Microwave assisted synthesis of biodegradable and bio-based polymers}

In this paragraph many works are mentioned and catalogued on the basis of the polymerization process: the next two sub paragraphs are dedicated, respectively, to step growth polymerizations and ring opening polymerizations. All the examples cited here deal with biodegradable or bio-based polymers (i.e. polymers totally or partly derived from renewable feedstocks) to emphasize the continuous diffusion and development of products with a more environmentally friendly perspective.

\subsection{Step growth polymerizations}

Step growth polymerizations generally involve bifunctional monomers yielding linear chains with functionalized terminations, capable of reacting with more monomer units. On account of the same principle, multifunctional monomers may be utilized to generate branched structures and thermosetting materials. The most common polymerizations in this class belong to the family of polycondensations, in which every coupling reaction implies the release of a small molecule (i.e. water).

\subsubsection{Aliphatic polyesters}

Among the conspicuous category of aliphatic polyesters many important examples of biodegradable and bio-based polymers can be found. An eco-friendly, solvent-free synthesis of poly(butylene succinate) (PBS) with a $\mathrm{M}_{\mathrm{w}}$ of $1.03 \times 10^{4} \mathrm{~g} / \mathrm{mol}$ and $2.35 \times 10^{4} \mathrm{~g} / \mathrm{mol}$ was achieved by the use of microwave heating at a temperature of, respectively, $200{ }^{\circ} \mathrm{C}$ and 220 ${ }^{\circ} \mathrm{C}$ (Scheme 1). An irradiation time of $20 \mathrm{~min}$ was needed, while poly(buthylene succinate) with a $\mathrm{M}_{\mathrm{w}}$ of $1.02 \times 10^{4} \mathrm{~g} / \mathrm{mol}$ was obtained by conventional heating in $5 \mathrm{~h}$. The polycondensation was performed under atmospheric pressure of $\mathrm{N}_{2}$, in the presence of 1,3dichloro-1,1,3,3-tetrabutyldistannoxane as catalyst (Velmathi et al., 2005).

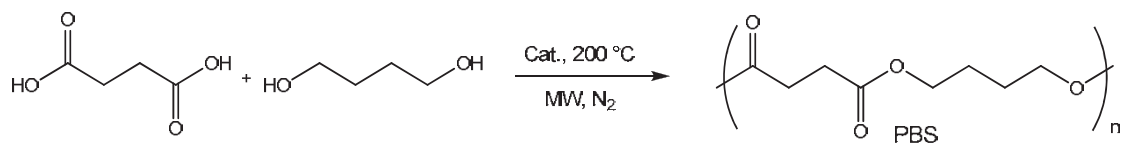

Scheme 1. Synthesis of poly(butylene succinate) (PBS).

Several authors accomplished the direct polycondensation of lactic acid to yield poly(lactic acid) (PLA) under microwave conditions. Ring opening polymerization of Lactide (the cyclic 
dilactone of lactic acid) is usually favored for the synthesis of relatively high molecular weight PLAs (see paragraph 2.2.3), nonetheless this single-step route is often attempted on account of its simplicity and low cost. In a former work D,L-Lactic acid was polymerized in bulk in a domestic microwave oven for $30 \mathrm{~min}$. at a power level of $650 \mathrm{~W}$, yielding oligomers with molecular masses ranging from 500 to $2000 \mathrm{~g} / \mathrm{mol}$. Reaction time was significantly shortened comparing to $24 \mathrm{~h}$ of conventional heating at $100^{\circ} \mathrm{C}$ and molecular masses were found to increase with irradiation time, while yields followed an opposite trend; after $20 \mathrm{~min}$. cyclic oligomers were also formed, affecting the physical properties of the product (Keki et al., 2001). More recently, $\mathrm{P}(\mathrm{L}) \mathrm{LAs}$ with markedly higher molecular masses $\left(\mathrm{M}_{\mathrm{w}} \approx 16,000 \mathrm{~g} / \mathrm{mol}\right)$ were obtained within $30 \mathrm{~min}$. of microwave irradiation employing a single-mode CEM Discover reactor set at a temperature of $200{ }^{\circ} \mathrm{C}$. A binary catalyst of $\mathrm{SnCl}_{2} / \mathrm{p}-\mathrm{TsOH}$ was used and the polycondensation was conducted at a reduced pressure $(30 \mathrm{mmHg})$ in order to remove water that progressively formed, avoiding the hydrolysis of the growing chain. Cyclic oligomers were still present as byproducts (Nagahata et al., 2007). Further enhancement was proposed in a later work by the use of solid super-acid (SSA) as a green heterogeneous catalyst: PLAs with molecular masses as high as 30,000 g/ mol were synthesized in 2-3 h irradiation times, after a water removal step under vacuum, at a temperature of $260{ }^{\circ} \mathrm{C}$ reached gradually. Interestingly, the authors claimed to save about $90 \%$ energy with respect to the time consuming (24-48 h) conventional heating procedure (Lei et al., 2009). A phenyl substituted derivative of lactic acid, precisely L-2-hydroxy-3-phenylpropanoic acid, was also polymerized in a domestic microwave oven with a maximum power of $510 \mathrm{~W}$ : molecular masses, quite low in any case, were found to increase with irradiation time, ranging from 1,800 g/ mol within 30 min. to $5,400 \mathrm{~g} / \mathrm{mol}$ within $2.5 \mathrm{~h}$ (L. Liu et al. 2001).

\subsubsection{Other step growth polymerizations}

The polycondensation of sebacic acid and $\omega$-amino alcohols was performed in a variable frequency microwave reactor to yield poly(amide-ester)s with impressive mechanical properties yet susceptible to degradability by proteolytic enzymes. Temperature was set at $180^{\circ} \mathrm{C}, 200^{\circ} \mathrm{C}$ and $220^{\circ} \mathrm{C}$ depending on the chosen amino alcohol and regulated by an on off power switching; power level was kept relatively low $(50-70 \mathrm{~W})$ due to the strong absorption of the starting materials. Reaction time was reduced from $3 \mathrm{~h}$ of conventional heating to $1 \mathrm{~h}$ of microwave irradiation, while product yields, molecular masses, and physico-chemical properties were found to be equal or higher (Borriello et al. 2007). Poly(anhydride)s are studied since long time as drug delivery systems with a tunable surface erosion: the synthesis of several poly(anhydride)s from aliphatic and aromatic diacids were conducted under microwave conditions to reduce reaction times from $3 \mathrm{~h}$ to 6$20 \mathrm{~min}$ at atmospheric pressure. Molecular weights were similar to the product of conventional heating; working under vacuum, as well as the isolation of an intermediate acetylated prepolymer, was not necessary, drastically simplifying the synthetic procedure (Vogel et al., 2003). With the aim of valorizing renewable feedstocks, interesting poly(ether)s were synthesized from isosorbide (1,4:3,6-dianhydrosorbitol) and 1,8-dibromoor 1,8-dimesyl-octane using phase transfer catalysis under microwave irradiation. A monomodal Synthwave 402 reactor, manufactured by Societè Prolabo, allowed to regulate temperature by modulating the emitted field and to monitor the reaction temperature on the surface of the vials by an infrared detector; toluene $(1 \mathrm{~mL}$ for $5 \mathrm{mg}$ of reagents) was used as a solvent to enhance temperature control and lower the mixture viscosity. Several advantages using microwave heating were reported: similar yields were obtained in $30 \mathrm{~min}$ 
instead of 1 day of reaction in an oil bath; products showed higher molecular weights and better homogeneities; a different termination mechanism generates ethylenic instead of hydroxylated chain ends (Chatti et al., 2002). Few years later the same group described the synthesis of novel poly(ether-ester)s from adipoyl chloride and aliphatic diols derived from isosorbide: polycondensations under microwave conditions proceeded five times faster $\left(95 \%\right.$ yield after $5 \mathrm{~min}$ at $\left.150{ }^{\circ} \mathrm{C}\right)$ and the polymer showed higher molecular weights $\left(\mathrm{M}_{\mathrm{W}}=\right.$ $4,200 \mathrm{~g} / \mathrm{mol}$ vs $4,050 \mathrm{~g} / \mathrm{mol}$ obtained by thermal heating). It is worth noting that, considering the identical temperature profiles generated by the two heating procedures, the better results shown by microwave irradiation are ascribed by the authors to "specific microwave features" such as the extension of polarity in the transition state comparing to the ground state (Chatti et al., 2006). Biodegradable, low molecular weight poly(alkylene hydrogen phosphonate)s were synthesized by a transesterification reaction of dimethyl hydrogen phosphonate with PEG 400 under microwave irradiation. Slightly higher temperatures were reached during the polymerization and markedly reduced reaction times (55 min vs $9 \mathrm{~h}$ of conventional heating) were observed, which avoided the undesirable thermal degradation of dimethyl hydrogen phosphonate (Bezdushna et al., 2005).

\subsection{Ring opening polymerizations}

Ring opening polymerizations (ROPs) are nowadays widespread and very popular synthetic routes. The use of cyclic monomers exhibits some unquestionable advantages for the preparation of high molecular weight polymers since no byproduct (e.g. water) is released during the propagation step, avoiding chain scission as well as competition with monomers and consequential early chain termination. In some cases ring strain may also play a role in favoring the polymerization thermodynamically.

\subsubsection{Poly( $\varepsilon$-caprolactone)}

Poly( $\varepsilon$-caprolactone) (PCL) is not produced from renewable resources, nonetheless, in the continuously developing class of biodegradable polymers, it proved to be one of the most useful and attractive: the number of works in scientific literature concerning this polymer is indeed impressive, and several successful microwave assisted syntheses are reported. An early example of microwave assisted synthesis employed titanium tetrabutylate as catalyst and an impressively refined custom monomodal reactor: conversion, measured by means of viscosity build-up, and number average molecular weights were close to those observed for conventionally heated procedure and did not indicate any advantage in using microwave irradiation (Albert et al., 1996). Poly(caprolactone) with weight-average molar mass $\left(\mathrm{M}_{\mathrm{w}}\right)$ over $4 \times 10^{4}$ was prepared by metal free, microwave assisted ring opening polymerization initiated by benzoic acid: the authors indicate that the ratio of polymer chain propagation was directly proportional to temperature between $160{ }^{\circ} \mathrm{C}$ and $230{ }^{\circ} \mathrm{C}$, while above this interval the synthesized PCL degraded. A multimodal domestic MW oven was employed: power was modulated by power on-off cycles, temperature was monitored by a tingrounded thermocouple and the reactions were performed in vacuum sealed ampoules. As stated by the authors, the advantage of microwave irradiation was the significantly enhanced propagation ratio of PCL chain while the formation of growing centers was greatly inhibited (Yu \& Liu, 2004). Earlier, the same group compared the synthesis of PCL initiated by benzoic acid and chlorinated acetic acids (Fig. 4): in both cases higher $\mathrm{M}_{\mathrm{w}}$ values and lower polydispersity indexes were observed with respect to conventional heating for an 
equal reaction time, nonetheless the molar masses of polymers synthesized employing chlorinated acids were lowered by degradation processes (Yu et al., 2003).
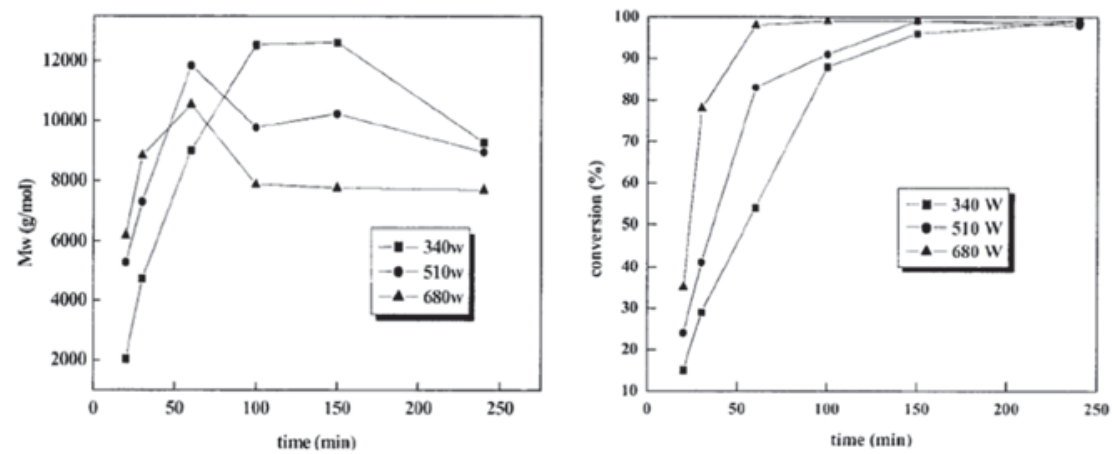

Fig. 4. Mw (left) and conversion (right) vs irradiation time for the ROP of $\varepsilon$-caprolactone initiated by chloroacetic acid $(\mathrm{M} / \mathrm{I}=15)$ (from Z. J. Yu, L. J. Liu, R. X. Zhuo, MicrowaveImproved Polymerization of $\varepsilon$-Caprolactone Initiated by Carboxilic Acids, Journal of Polymer Science: Part A: Polymer Chemistry, 2003, 41, 13-21. Copyright Wiley-VCH Verlag $\mathrm{GmbH} \& \mathrm{Co}$. KGaA. Reproduced with permission).

A lipase-catalyzed microwave assisted synthesis of PCL was attempted in several solvents at their boiling point and remarkably different behaviors were observed: while the reactions in toluene and benzene proceeded slower compared to oil bath heating, the reaction in diethyl ether showed an increased rate. It is known that the activity of the catalyst Novozyme 435, depends on temperature and on the polarity of the medium: no polymerization was indeed observed in polar solvents like THF or dioxane. Microwave irradiation was performed with a monomodal CEM-Discover device, equipped with a CEM fiber optic temperature sensor, for 90 min under reflux conditions (Kerep \& Ritter, 2006). A "green" synthesis was described to obtain poly( $\varepsilon$-caprolactone)s with molar masses ranging from 3,000 g/mol to $16,000 \mathrm{~g} / \mathrm{mol}$ : no solvent was used and non toxic, biologically acceptable lanthanide halides were chosen as initiators. Two different microwave equipments were employed: a monomodal Prolabo Synthwave S402 equipped with an IR temperature sensor (15 to $45 \mathrm{~min}$ of irradiation at $180-200{ }^{\circ} \mathrm{C}$ ) and a Sairem GMP $12 \mathrm{~T}$ provided with a Marconi F1192-12 water-cooled circulator (3 to $20 \mathrm{~min}$ of irradiation at $230{ }^{\circ} \mathrm{C}$ ). Interestingly, the degradation rate of PCL was also assessed: it was found that the slow hydrolytic process is accelerated by the catalyst, while the faster enzymatic process is inhibited (Barbier-Baudry et al., 2003). The $\mathrm{Sn}(\mathrm{Oct})_{2}$ catalyzed microwave assisted polymerization of $\varepsilon$-caprolactone $(\varepsilon-\mathrm{CL})$ can be initiated by methacrylic acid or acrylic acid yielding radical polymerizable PCL macromonomers. Reactions were carried out in a monomodal CEM Discover reactor at $180{ }^{\circ} \mathrm{C}$ for $90 \mathrm{~min}$ in bulk, under air; it is worth noting that the high temperature reached under microwave irradiation did not imply uncontrolled free radical polymerization processes, though in this case a comparison with classical thermal activation showed no significant acceleration effect (Sinwell et al., 2006). The kinetics of pure and zinc catalyzed ring opening polymerization of $\varepsilon$-caprolactone was also investigated in comparison to conventional heating syntheses and a model based on continuous distribution kinetics with time/temperature-dependent rate coefficients was 
proposed. From these coefficients the activation energies were calculated: while for pure thermal heating and catalyzed thermal heating the values were respectively 24.3 and 23.4 $\mathrm{kcal} / \mathrm{mol}$, the value found for catalyzed microwave heating was $5.7 \mathrm{kcal} / \mathrm{mol}$, reflecting the observed increment in the polymerization rate (Sivalingam et al., 2004). Kinetic investigations were also performed comparing the rate constant for the stannous octoate catalyzed ROP of $\varepsilon$-CL under microwave conditions and conventional heating. Several equilibrium temperatures were reached by means of different power levels: while conventional polymerizations followed Arrhenius' law, the rate of microwave assisted reactions (Fig. 5) showed an abnormal peak value for $180{ }^{\circ} \mathrm{C}$ (at $500 \mathrm{~W}$ ), inducing the authors to suggest the hypothesis of non-thermal microwave effects (Li et al., 2007).

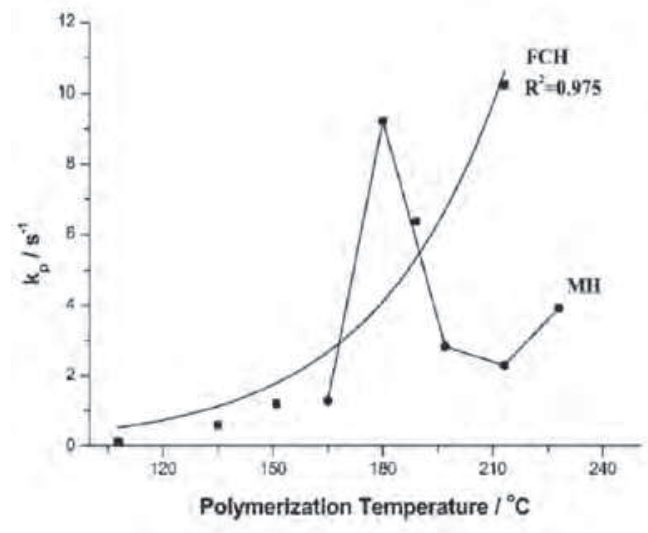

Fig. 5. Chain propagation rate constant $\left(\mathrm{k}_{\mathrm{p}}\right)$ for the ROP of $\varepsilon$-caprolactone by microwave heating (circles) and conventional heating (squares) (from H. Li, L. Liao, L. Liu, Kinetic Investigation into the Non-Thermal Microwave Effect on the Ring Opening Polymerization of $\varepsilon$-Caprolactone, Macromol. Rapid Commun., 2007, 28, 411-416. Copyright Wiley-VCH Verlag $\mathrm{GmbH} \& \mathrm{Co}$. KGaA. Reproduced with permission).

Combining ring opening polymerization and microwave assisted "click" chemistry, acetylenefunctionalized PCL was synthesized and reacted with heptakis-azido- $\beta$-cyclodextrin to obtain star shaped polymers. A tetra-arm metallopolymer was also achieved by the "supramolecular click" reaction between di(pyridinyl)piridazine-functionalized macroligands and Copper (I) ions (Hoogenboom et al., 2006). The 1-butyl-3-methylimidazolium tetrafluoroborate ionic liquid has been successfully used as solvent for the ROP of $\varepsilon$-caprolactone: on account of its efficient microwave energy absorption. PCL with $\mathrm{M}_{\mathrm{w}}$ of $28,500 \mathrm{~g} / \mathrm{mol}$ was obtained by means of a multimodal domestic oven at $85 \mathrm{~W}$ for $30 \mathrm{~min}$, using Zinc oxide as catalyst (Liao et al., 2006). A large scale synthesis was recently performed using up to $2.45 \mathrm{Kg}$ of monomer to assess the industrialization possibilities of microwave assisted $\varepsilon$-CL polymerization. A selfdesigned industrial microwave oven, capable of a maximum power of 6,000 W, was employed at different power levels and loaded with different amount of reactants: in any case the stannous octoate catalyzed ring opening polymerizations proceeded smoothly, yielding PCL with $\mathrm{M}_{\mathrm{w}}$ ranging from $66,000 \mathrm{~g} / \mathrm{mol}$ to $122,000 \mathrm{~g} / \mathrm{mol}$ ( $\mathrm{Xu}$ et al., 2010). The effects of the presence of diisopropyl hydrogen phosphonate $(2.9 \%)$ on the microwave assisted synthesis of PCL was examined, concluding that the ROP was initiated by traces of water but could be 
catalyzed by the oligo(e-caprolactone)-substituted hydrogen phosphonate resulting from transesterification reactions. A polymer with molecular weight of $8,100 \mathrm{~g} / \mathrm{mol}$ was obtained in $100 \mathrm{~min}$ at $510 \mathrm{~W}$ of irradiation power (Tan et al., 2009).

\subsubsection{Poly( $\varepsilon$-caprolactone) copolymers}

One of the first examples of microwave assisted synthesis of PCL copolymers was performed by means of a variable frequency device operated in the range from 0.4 to

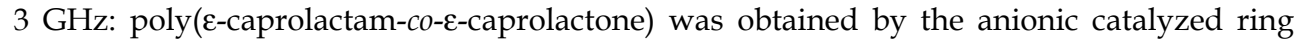
opening of the two cyclic monomers (both showed effective radiation absorption). Compared to conventional procedures, higher yields and higher amide content were observed, the latter implying a higher value for the glass transition temperature $\left(\mathrm{T}_{\mathrm{g}}\right)$ of the copolymer (Fang et al., 2000). More recently, a series of completely biodegradable poly(vinyl alcohol)-graft-poly( $\varepsilon$-caprolactone) comb-like copolymers were prepared employing poly(vinyl alcohol) as an initiator for the microwave assisted ROP of $\varepsilon$-CL. The authors report a degree of polymerization (DP) for PCL in the range of 3-24 and a degree of substitution (DS) of PVA from 0.35 to 0.89 and specify that both values were enhanced by microwave heating: irradiation was carried out at three power levels (340, 510 and $680 \mathrm{~W})$, finding that the higher power provided higher DPs and DSs (Yu \& Liu, 2007). Amphiphilic di-block PEG- $b$-PCL copolymers were synthesized in a one pot procedure under microwave irradiation using PEG monomethyl ester as oxydrilic initiator and boron trufluoride, Sodium hydride or stannous octoate as alternative catalysts, the latter yielding polymers with the highest purity (Ahmed et al., 2009). By means of a similar procedure, different authors obtained PEG- $b$-PCL copolymers with $M_{\mathrm{w}}$ values ranging from $5,800 \mathrm{~g} / \mathrm{mol}$ to $14,500 \mathrm{~g} / \mathrm{mol}$ and very low polydispersity indexes $(\leq 1.19)$. A comparison with oil-bath heating synthesis showed a dramatic reduction of reaction time under microwave conditions: analogous conversions were obtained after 45 min instead of 1 day (Karagöz \& Dinçer, 2010). Biodegradable poly( $\varepsilon$-caprolactone)-co-poly(p-dioxanone) random copolymers with $\mathrm{M}_{\mathrm{w}}$ in the $120,000-180,000 \mathrm{~g} / \mathrm{mol}$ range and polydispersity indexes around 2 were synthesized by ring opening polymerization of the two cyclic co-monomers under microwave irradiation. The reaction was completed within $20 \mathrm{~min}$ at $140{ }^{\circ} \mathrm{C}$ : after $30 \mathrm{~min}$ the conversion of $\varepsilon$-CL remained constant, while the conversion of $p$-DO slightly decreased (Chen et al., 2010).

\subsubsection{Poly(lactic acid)}

Even though poly(lactic acid) can be synthesized by direct polycondensation of lactic acid (see paragraph 2.1.1), polymers with higher molecular weights and lower polydispersity indexes are commonly obtained by ring opening polymerization of lactide (i.e. the cyclic dilactone of lactic acid) (Scheme 2). LL- and DD-lactide yield semi crystalline polymers named P(L)LA and $\mathrm{P}(\mathrm{D}) \mathrm{LA}$, while rac-lactide is used to synthesize amorphous polymers named P(LD)LA. On account of its attractive physico-chemical properties and its biodegradability, PLA is widely used as bio-based, large scale packaging material and in a number of biomedical applications, hence it represents a subject of extensive research. A stannous octoate catalyzed microwave assisted synthesis of $\mathrm{P}(\mathrm{LD}) \mathrm{LA}$ was reported without the need of an inert atmosphere during irradiation. Using a domestic oven set at a power level of $450 \mathrm{~W}$ for $30 \mathrm{~min}$ a polymer with viscosity-average molecular weight over $200,000 \mathrm{~g} / \mathrm{mol}$ was obtained in $85 \%$ yield; the reaction was carried out in bulk, using open vessels and adding carborundum 
$(\mathrm{SiC})$ to the mixture as microwave absorber. It is worth noting that, comparing the temperature in microwave and conventional conditions, the occurrence of both thermal and non-thermal microwave effects is claimed by the authors (Jing et al., 2006). In a different study, by means of an analogous procedure (except in this case the polymerization took place under vacuum) $\mathrm{P}(\mathrm{LD}) \mathrm{LA}$ with weight-average molecular weight ranging from $97,000 \mathrm{~g} / \mathrm{mol}$ to $185,000 \mathrm{~g} / \mathrm{mol}$ and polydispersity indexes around 2 were obtained in $90 \%$ yield within 10 min.

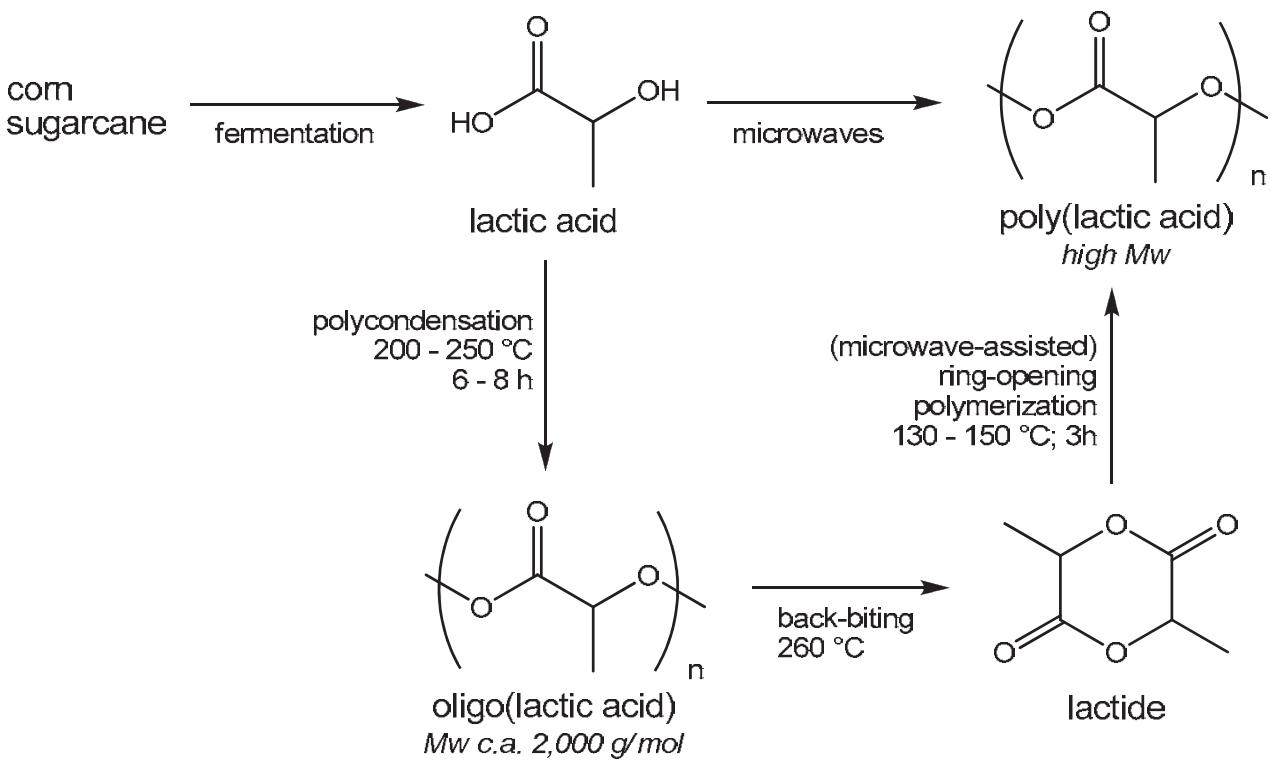

Scheme 2. Synthetic routes to high Mw poly(lactic acid).

Optimal results were achieved setting the power level at $255 \mathrm{~W}$, while reactions carried out at $340 \mathrm{~W}$ or more showed a significant degradation of the product (C. Zhang et al., 2004). According to other authors, the reaction rate in the ROP of L-lactide increases linearly with power output (tested up to 1,300 W), though molecular weights (and consequently degradation phenomena) were not monitored for P(L)LA (Koroskenyi \& McCarthy, 2002). The synthesis of relatively high molecular weight P(LD)LA (ranging from $26,700 \mathrm{~g} / \mathrm{mol}$ to $112,500 \mathrm{~g} / \mathrm{mol}$ ) was recently carried out in a CEM Discover monomodal $\mathrm{MW}$ reactor set at $100{ }^{\circ} \mathrm{C}$ for $30 \mathrm{~min}$. Stannous octoate in low quantities with respect to monomer $(0.1 \mathrm{~mol} \% ; 0.02 \mathrm{~mol} \%$ and $0.01 \mathrm{~mol} \%)$ was used as catalyst; the reaction was carried out in bulk, under reduced pressure (Nikolic et al., 2010). P(LD)LA with a high viscosity-average molecular weight $(159,200 \mathrm{~g} / \mathrm{mol})$ could also be obtained, in similar conditions, by means of a modified domestic oven capable of a continuous microwave irradiation: the authors report a good yield $(81.1 \%)$ after only $10 \mathrm{~min}$ at a low power level of $90 \mathrm{~W}$ (Y. Zhang et al., 2009). In a recent work an innovative calix[4]arene$\mathrm{Ti}(\mathrm{IV})$ catalyst (Fig. 6) was employed in the bulk ring opening polymerization of L-lactide 
under microwave irradiation. A CEM Discover S-class monomodal reactor was operated at a maximum power level of $200 \mathrm{~W}$ for variable reaction times: a conversion of $85 \%$ was registered after $40 \mathrm{~min}$ of irradiation reaching $95 \%$ after $80 \mathrm{~min}$; longer times led to decomposition phenomena. Compared to conventional synthesis, microwave heating markedly reduced reaction times but slighltly lowered the control over molecular weights and polydispersity indexes (Frediani et al., 2010).

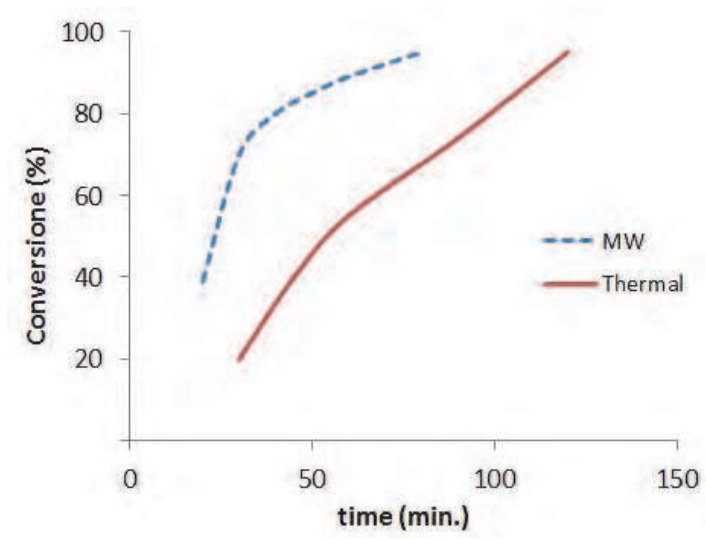

Fig. 6. Conversion vs reaction time for the ROP of L-lactide (left) and the employed calix[4]arene-Ti catalyst (see Frediani et al., 2010).

\subsubsection{Poly(lactic acid) copolymers}

Fully biocompatible and biodegradable poly(glycolic acid-co-lactic acid) copolymers with potential applications in the biomedical field were synthesized by ring opening polymerization: stannous octoate was used as catalyst $(0.03 \mathrm{~mol} \%)$ and octadecanol as the oxydrylic initiator $(0.01 \mathrm{~mol} \%)$. Microwave irradiation was performed in a MAS-II scientific reactor at a temperature of $120{ }^{\circ} \mathrm{C}$ for a variable time ( $3 \mathrm{~min}$ to $9 \mathrm{~min}$ ), under nitrogen atmosphere: different glycolic acid (GA) : lactic acid (LA) feed ratios were assessed and yields ranged from $69 \%$ to $86 \%$. It is worth noting how the products showed higher GA content compared to the feed ratio, and that copolymers with higher GA content were characterized by decreased glass transition temperature and increased melting temperature (G. Li et al., 2010). Amphiphilic, biodegradable PLLA- $b$-PEG- $b$-PLLA triblock copolymers were synthesized by microwave assisted ring opening polymerization of L-lactide employing poly(ethylene glycol) (PEG2000) as a difunctional oxydrylic initiator (Scheme 3).<smiles>CC1OC(=O)C(C)OC1=O</smiles>

lactide

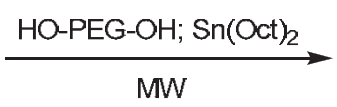

MW<smiles>CC(=CC(C)(C)OC(C)C(=O)OC(C)C)C(C)OC(C)C</smiles>

triblock copolymer

Scheme 3. Synthesis of PLA- $b$-PEG- $b$-PLA triblock copolymer. 
A surprisingly short irradiation time of $3 \mathrm{~min}$ at $100{ }^{\circ} \mathrm{C}$ in a CEM Discover reactor was enough to achieve $92 \%$ lactide conversion, yielding a copolymer with a number average molecular weight of $28,230 \mathrm{~g} / \mathrm{mol}$. It was observed that longer PLLA segments (i.e. higher PLLA content) induced higher glass transition and melting temperatures (C. Zhang et al., 2007).

\subsubsection{Other ring opening polymerizations}

Stannous octoate catalyzed ring opening polymerization of $p$-dioxanone was conducted under microwave irradiation to obtain (63\% yield) biodegradable PDDO with a viscosity average molecular weight of $156,000 \mathrm{~g} / \mathrm{mol}$. A domestic oven was employed for this study and several power level tested: $270 \mathrm{~W}$ for $25 \mathrm{~min}$ proved to be the most favorable choice, allowing a dramatic increase in the reaction rate compared to the $14 \mathrm{~h}$ of heating required by conventional procedures in analogous conditions (Y. Li et al., 2006). Poly(trimethylen carbonate) (PTMC) is a promising, biocompatible poly(alkyl carbonate) with good mechanical properties: a PTMC-b-PEG-b-PTMC triblock copolymers with tunable degradation properties were synthesized by catalyst-free microwave assisted ring opening polymerization of TMC using PEG600, PEG1000 and PEG2000 as a difunctional oxydrylic initiators. It was observed that the molar mass of the copolymer and the TMC conversion reached a maximum after $30 \mathrm{~min}$ at $120{ }^{\circ} \mathrm{C}$ (Fig. 7): further irradiation or higher temperatures induced product degradation phenomena (Liao et al., 2008).
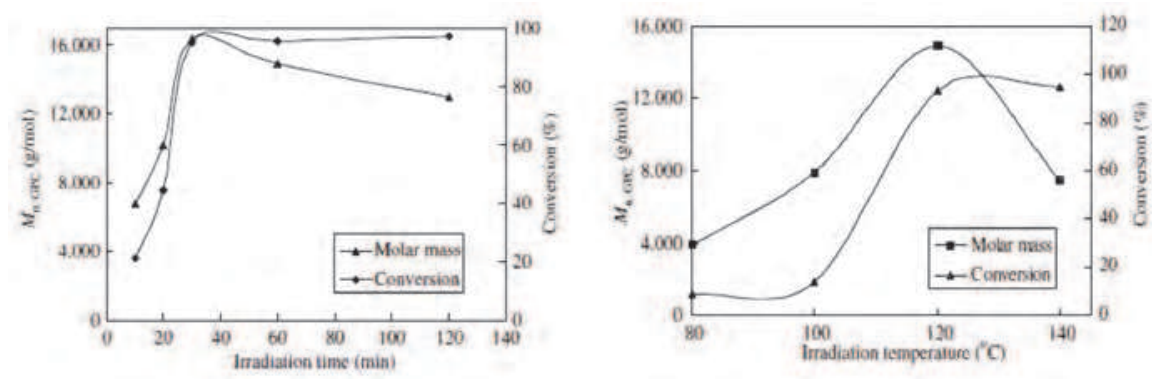

Fig. 7. Synthesis of a PTMC- $b$-PEG- $b$-PTMC copolymer: effect of irradiation time (left) and temperature (right) on Mn and conversion (from Liqiong Liao, Chao Zhang, Shaoqin Gong, Preparation of Poly(trimethylene carbonate)-block-poly(ethylene glycol)-blockpoly(trimethylene carbonate) Triblock Copolymers under Microwave Irradiation, Reactive \& Functional Polymers, 2008, 68, 751-758. Copyright Elsevier Ltd. Reproduced with permission).

The ring opening of cyclohexene-oxide in the presence of $\mathrm{CO}_{2}$ for the synthesis of biodegradable aliphatic poly(ether-carbonate)s was investigated in order to employ a troublesome waste product as feedstock for the production of useful materials. Double metal cyanide complex catalysts based on $\mathrm{Zn}_{3}\left[\mathrm{Co}(\mathrm{CN})_{6}\right]$ were profitably utilized and microwave irradiation was chosen as heating method, with strong beneficial effects on polymerization times and $\mathrm{CO}_{2}$ incorporation grade (Dharman et al., 2008). Poly(oxazoline)s are relatively non toxic polymers with attractive properties for biomedical applications, nonetheless they cannot be classified as biodegradable or bio-based polymers: comprehensive reviews about microwave assisted synthesis in this class of products can be found elsewhere (Adams \& Schubert, 2007; Makino \& Kobayashi, 2010; Wiesbrock et al., 2004). 


\section{Microwave assisted modification and processing}

In this paragraph we review a number of papers exemplifying how microwave irradiation can also be employed for the chemical modification and processing of natural abounding or synthetic polymers. Some studies deal with non biodegradable oil-based polymers: these works are reported anyway, since our attention here mostly focuses on the processing technique rather than the polymer itself.

\subsection{Grafting and chemical modification of natural polymers}

Chemical modification of natural polymers, most commonly polysaccharides, is a clever way to obtain new materials from abundant renewable feedstocks. A very effective approach to this task is the design of graft copolymers in which the former natural polymer constitutes the backbone and is covalently bound to numerous branches of synthetic polymer. For example, in order to obtain a biodegradable amphoteric material, chitosan was first reacted with phtalic anhydride to protect the amino groups along the chain and then used as an oxydrylic initiator for the stannous octoate catalyzed ROP of $\varepsilon$-caprolactone: after deprotection a chitosan-g-PCL copolymer with grafting percentage above $100 \%$ by weight was obtained and characterized (Scheme 4). The polymerization step was carried out smoothly under microwave irradiation using a domestic oven and best results in terms of increased reaction rate were obtained with high power levels of $450 \mathrm{~W}$ and $600 \mathrm{~W}$ (L. Liu et al., 2005). The $\beta$-cyclodextrin functionalization of chitosan was also performed under microwave irradiation yielding graft copolymers with a superior lead adsorption capacity if compared to analogous products obtained by conventional heating. The authors report that a superior yield was achieved despite the fact that no redox initiator was required (Sharma \& Mishra, 2010). It is worth noting that chitosan itself can be obtained from chitin via a microwave mediated deacetylation reaction (Sahu et al., 2009). With a similar approach, PCL side chains were grafted onto pea starch (35\% amylose, $65 \%$ amylopectin) in a microwave assisted (255 W for $3 \mathrm{~min}$ ) one pot synthesis yielding a thermoformable hydrophobic copolymer with promising properties as eco-friendly or biomedical material. Regrettably, not much about the utilized microwave heating setup is reported by the authors (Chang et al., 2009). An efficient superabsorbent material capable of a high swelling ratio in distilled water was synthesized grafting sodium acrylate onto cornstarch under microwave irradiation and using potassium persulfate as initiator. Microwave power is reported to be the most influent factor to obtain best performing copolymers (i.e. with higher swelling ratio and lower solubility): $10 \mathrm{~min}$ of irradiation at $85-90 \mathrm{~W}$ proved to be the most suitable heating conditions (Tong \& al., 2004). The microwave assisted preparation of a poly(acrylamide)-g-starch copolymer with promising properties as a flocculant for water treatment was recently described using ceric ammonium nitrate as initiator. The authors report high grafting rates and superior yields compared to the conventional procedure. Despite the use of a domestic $800 \mathrm{~W}$ microwave oven, and the manual switching off of irradiation whenever the reaction mixture was about to boil, reproducibility is claimed to be one of the advantages over ordinary methods (S. Mishra et al., 2011). Cellulose, being the most abundant natural polysaccharide, is also attracting a huge attention and indeed several examples of its chemical modification can be found in literature. Microwave heating was employed for the synthesis of common cellulose derivatives like esters (Satgé et al., 2002) and carbammates (Guo et al., 2009) as well as for the graft copolymerization of methyl methacrylate initiated with ceric amonium nitrate (Wan et al., 2011). Guar Gum is an edible 
galactomannan isolated from a legume native of the northwestern India and finds wide application as water thickener due to the ability of forming highly viscous colloidal dispersions. In order to tune its physicochemical and degradation properties a number of microwave assisted derivatizations were successfully carried out by the same group within short irradiation times. We report, among these, a poly(ethyl acrylate) graft copolymer for efficient removal of cadmium(II) from aqueous phases (Singh et al., 2009); a poly(acrylonitrile) graft copolymer with high water absorbing capacity (Singh et al., 2004) and the first example of poly(acrylamide) graft copolymer (Singh et al., 2004). It is worth noting how the authors achieve these results in the absence of redox initiators or catalysts: this is due, in their view, to non thermal effects and to radical formation as a consequence of molecular friction under microwave heating. Salient papers regarding microwave assisted synthesis deal also with grafting of methyl methacrylate onto carrageenan in which backbone decomposition is prevented by short reaction times (Prasad et al., 2006); poly(acrylonitrile)-g-xyloglucan copolymers by an initiator-free preparation method (A. Mishra et al., 2008) and poly(acrylic acid) grafting of Cassia Javanica seed gum to obtain a sorbent material for $\mathrm{Hg}$ (II) removal (Singh et al., 2010).

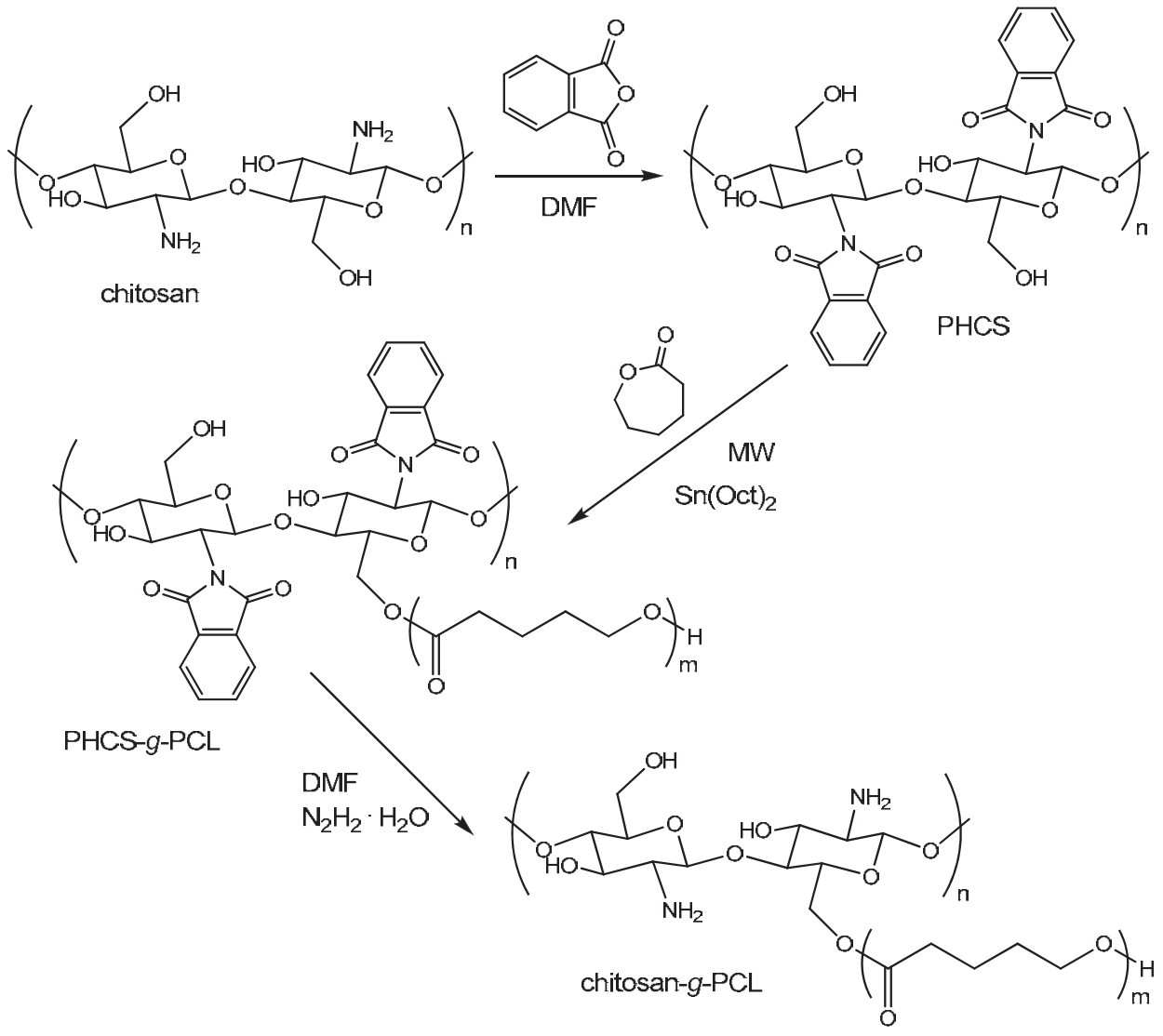

Scheme 4 . Synthesis of a chitosan-g-PCL copolymer. 


\subsection{Polymer processing}

With the development of industrial scale dedicated devices, microwave polymer processing techniques are nowadays sensible alternatives to conventional heating methods, setting new benchmarks in terms of time and energy efficiency. Comprehensive reviews about this chief research field can be found in literature (Clark \& Sutton, 1996; Das et al., 2008; Leonelli \& Mason, 2010; Thostenson \& Chou, 1999); our aim here is to introduce some representative examples dealing with a variety of applications ranging from polymer crosslinking to welding of thermoplastics. Short irradiation times and a relatively low temperature $\left(100^{\circ} \mathrm{C}\right)$ turned out to be sufficient to carry out the one-pot crosslinking reaction of poly(vinyl alcohol) in the presence of metal salts, yielding polymer-inorganic nanocomposites with several different morphologies. On account of the good control over nanostructure's shape and size distribution and considering that similar products were previously prepared via hydrothermal treatment at $200{ }^{\circ} \mathrm{C}$ in $72 \mathrm{~h}$, the efficiency of microwave heating applied to these syntheses results clear (Polshettiwar et al., 2009; Varma \& Nadagouda, 2007). Polymer surface modification has been performed by a microwave induced plasma treatment (Leonelli \& Mason, 2010): to cite an example, poly(dimethylsiloxane) (PDMS) slabs were irreversibly sealed within 30-60s by means of a $30 \mathrm{~W}$ plasma generated in glass bottles containing 2-3 Torr of oxygen (Hui et al., 2005). Similar procedures are reported in papers dealing with modification of PDMS surface hydrophilicity (Ginn \& Steinbock, 2003) and polyaniline-aided welding of high density poly(ethylene) (Wu \& Benatar, 1997). Welding of thermoplastics such as ultra high molecular weight polyethylene (UHMW PE), polycarbonate and ABS could be achieved by focused microwave irradiation of the specimen joint interface (Yarlagadda \& Chai, 1998). An interesting comparison between thermal curing and microwave curing of the E44 epoxy resin showed a significant reduction of processing time and temperature; a lower quantity of curing agent (i.e. maleic anhydride) was needed under microwave irradiation and products with improved compressive strength and bending strength are obtained by the authors (Zhou et al., 2003). In a recent work epoxies of linseed oil and dehydrated castor oil were blended with PVA within 2 min of microwave irradiation $\left(75^{\circ} \mathrm{C} ; 350 \mathrm{~W}\right)$ with the aim to develop new biobased materials with desirable properties for packaging and mulching: as usual, the chief advantage over conventional blending procedures is reported to be the extremely short processing time (Riaz et al., 2011). According to several authors, microwave foaming under vacuum (Jaja \& Durance, 2008) or at atmospheric pressure (Torres et al., 2007) proved to be an effective route to obtain porous materials for tissue engineering applications from polymeric gels. It is worth reminding that microwave transparent polymers, such as HDPE, may easily be processed employing microwaves as energy source in the presence of highly absorbing fillers and additives like carbon black (F. Liu et al., 2010). Theoretical models have also been developed to investigate the optimal conditions for an efficient heating: in a recent study the application of microwaves on natural rubber and Nylon 66 slabs was analyzed highlighting the role of irradiation pulsing parameters and ceramic support plates (Durairaj \& Basak, 2009).

\section{Conclusion}

During the last decade, the diffusion of reliable research devices turned microwave assisted polymer chemistry from pioneering curiosity to realistic alternative heating technique, while increased knowledge and engineering contributed to optimize well established polymer processing methods. Increased reaction rates under microwave conditions are reported by virtually every paper in the related literature and time saving is widely recognized as the 
most obvious advantage over conventional heating. Even though the explanations for this beneficial effect are sometimes controversial, many authors nowadays tend to exclude the occurrence of non-thermal phenomena and rather focus on faster energy transfer, higher local temperatures or solvents overheating. Higher products yields are often, yet not univocally, mentioned as one of the relevant features provided by microwave reactors, as well as altered selectivities, probably related to differential radiation absorption, are described in some cases. Some experiments show how products purity may be improved under microwave conditions, minimizing detrimental side reactions by a more homogeneous heating and reduced reaction times. Despite these remarkable points, assessing how "green" microwaves are in terms of energy efficiency seems not to be straightforward: indeed several papers report efficiencies which closely compare with conventional oil baths and mantles (Devine \& Leadbeater, 2011; Gronnow et al., 2005; Moseley \& Kappe, 2011; Razzaq \& Kappe, 2008). The choice of a specific experimental setup notably influences the overall balance and particularly important appear to be the reaction scale, the use of monomodal or multimodal devices and open or pressurized vials, nonetheless the relatively low efficiency of magnetrons (40\% to 65\%) generally counterweight the much shorter reaction times. All things considered, energy efficiency of microwave assisted chemistry should not be taken for granted but carefully evaluated case by case.

\section{Acknowledgment}

Authors would like to thank MIUR (PRIN 2008 project 200898KCKY - 'Inorganic nanohybrids based on bio-polyesters from renewable resources') and Regione Toscana ('Competitività regionale e occupazione' 2007-2013 - project TeCon@BC, POR-FESR 20072013) for financial support.

\section{References}

Adams, N. \& Schubert, U. S. (2007). Poly(2-oxazolines) in Biological and Biomedical Applications. Advanced Drug Delivery Review, Vol. 59, No. 15 (December 2007), pp. 1504-1520, ISSN: 0169-409X

Ahmed, H.; Trathnigg, B.; Kappe, O. \& Saf, R. (2009). Characterization of Poly(ethylene glycol)-b-poly(e-caprolactone) by Liquid Chromatography under Critical Conditions: Influence of Catalysts and Reaction Conditions on Product Composition. European Polymer Journal, Vol. 45, No. 8 (August 2009), pp. 2338-2347, ISSN: 0014-3057

Albert, P.; Warth, H.; Mülhaupt, R. \& Janda, R. (1996). Comparison of Thermal and Microwave-Activated Polymerization of $\varepsilon$-Caprolactone with Titanium Tetrabutylate as Catalyst. Macromolecular Chemistry and Physics, Vol. 197, No. 5 (May 1996), pp. 1633-1641, ISSN: 1022-1352

Barbier-Baudry, D.; Brachais, L.; Cretu, A.; Gattin, R.; Loupy, A. \& Stuerga, D. (2003). Synthesis of Polycaprolactone by Microwave Irradiation - an Interesting Route to Synthesize this Polymer via Green Chemistry. Environmental Chemical Letters, Vol. 1, No. 1, (January 2003), pp. 19-23, ISSN: 1610-3661 
Bezdushna, E.; Ritter, H. \& Troev, K. (2005). Poly(alkylene hydrogen phosphonate)s by Transesterification of Dimethyl Hydrogen Phosphonate with Poly(ethylene glycol). Macromolecular Rapid Communications, Vol. 26, No. 6 (March 2005), pp. 471-476, ISSN: 1521-3927

Bogdal, D.; Penczek P.; Pielichowsky, J. \& Prociack, A. (2003). Microwave Assisted Synthesis, crosslinking and Processing of Polymeric Materials. Advances in Polymer Science, Vol. 163 (2003), pp. 193-263, ISSN: 0065-3195

Borriello, A.; Nicolais, L.; Fang, X.; Huang, S. J. \& Scola, D. A. (2007). Synthesis of Poly(amide-ester)s by Microwave Methods. Journal of Applied Polymer Science, Vol. 103, No. 3 (February 2007), pp. 1952-1958, ISSN: 0021-8995

Chang, P. R.; Zhou, Z.; Xu, P.; Chen, Y.; Zhou, S. \& Huang, J. (2009). Thermoforming Starchgraft-polycaprolactone biocomposites via One-pot Microwave Assisted Ring Opening Polymerization. Journal of Applied Polymer Science, Vol. 113, No. 5 (September 2009), pp. 2973-2979, ISSN: 0021-8995

Chatti, S.; Bortolussi, M.; Loupy, A.; Blais, J. C.; Bogdal, D. \& Majdoub, M. (2002). Efficient Synthesis of Polyethers from Isosorbide by Microwave-Assisted Phase Transfer Catalysis. European Polymer Journal, Vol. 38, No. 9 (September 2002), pp. 1851-1861, ISSN: 0014-3057

Chatti, S.; Bortolussi, M.; Bogdal, D.; Blais, J. C. \& Loupy, A. (2006). Synthesis and Properties of New Poly(ether-ester)s Containing Aliphatic Diols Based on Isosorbide. Effects of the Microwave-Assisted Polycondensation. European Polymer Journal, Vol. 42, No. 2 (February 2006), pp. 410-424, ISSN: 0014-3057

Chen, R.; Hao, J. Y.; Xiong, C. D. \& Deng, X. M. (2010). Rapid Synthesis of Biodegradable Poly(epsilon-caprolactone-co-p-dioxanone) Random Copolymers under Microwave Irradiation. Chinese Chemical Letters, Vol. 21, No. 2 (February 2010), pp. 249-252, ISSN: 1001-8417

Clark, D. E. \& Sutton, W. H. (1996). Microwave Processing of Materials. Annual Review of Material Science, Vol. 26, pp. 299-331, ISSN: 0084-6600

Das, S.; Mukhopadhyay, A. K.; Datta, S. \& Basu, P. (2008). Prospects of Microwave Processing: an Overview. Bulletin of Material Science, Vol. 31, No. 7 (December 2008), pp. 943-956, ISSN: 0973-7669

Devine, W. G. \& Leadbeater, N. E. (2011). Probing the Efficiency of Microwave Heating and Continuous-flow Conventional Heating as Tools for Organic Chemistry. Arkivoc, Vol. 2011, Part (v), pp. 127-143, ISSN:1424-6376

Dharman, M. M.; Ahn, J. Y.; Lee, M. K.; Shim, H. L.; Kim, K. H.; Kim, I \& Park, D. W. (2008). Moderate Route for the Utilization of $\mathrm{CO}_{2}$ - Microwave Induced Coploymerization with Cyclohexene Oxide Using Higly Efficient Double Metal Cyanide Complex Catalysts Based on $\mathrm{Zn}_{3}\left[\mathrm{Co}(\mathrm{CO})_{6}\right]$. Green Chemistry, Vol. 10, No. 6 (2008), pp. 678684, ISSN: 1463-9270

Deetlef, M. \& Seddon, K. R. (2003). Improved Preparation of Ionic Liquids Using Microwave Irradiation. Green Chemistry, Vol. 5, No. 2 (2003) pp. 181-186, ISSN: 1463-9270

Durairaj, S. \& Basak, T. (2009). Analysis of Pulsed Microwave Processing of Polymer Slabs Supported With Ceramic Plates. Chemical Engineering Science, Vol. 64, No. 7 (April 2009), pp. 1488-1502, ISSN: 0009-2509 
Fang, X.; Hutcheon, R. \& Scola, D. A. (2000). Microwave Syntheses of Poly( $\varepsilon$-caprolactam-co$\varepsilon$-caprolactone). Journal of Polymer Science - Part A: Polymer Chemistry, Vol. 38, No. 8 (April 2000), pp. 1379-1390, ISSN: 1099-0518

Frediani, M.; Sémeril, D.; Matt, D.; Rizzolo, F.; Papini, A. M.; Frediani, P.; Rosi, L.; Santella, M. \& Giachi, G. (2010). L-Lactide Polymerization by Calix[4]arene-titanium (IV) Complex Using Conventional Heating and Microwave Irradiation. e-Polymers, No. 019 (February 2010) pp. 1-8, ISSN: 1618-7229

Ginn, B. T. \& Steinbock, O. (2003). Polymer Surface Modification Using Microwave-OvenGenerated Plasma. Langmuir, Vol. 19, No. 19 (September 2003), pp. 8117-8118, ISSN: 0743-7463

Glasnow, T. N. \& Kappe, C. O. (2007). Microwave-Assisted Synthesis Under Continuous Flow Conditions. Macromolecular Rapid Communications, Vol. 28, No. 4 (February 2007), pp. 395-410, ISSN: 1521-3927

Gronnow, M. J.; White, R. J.; Clark, J. H. \& Macquarrie, D. J. (2005). Energy Efficiency in Chemical Reactions: a Comparative Study of Different Reaction Techniques. Organic Process Research E Engineering, Vol. 9, No. 4 (July 2005), pp. 516-518, ISSN: 1083-6160

Guerrero-Sanchez, C.; Lobert, M.; Hoogenboom, R. \& Schubert, U. S. (2007). Microwave Assisted Homogeneous Polymerizations in Water-Soluble Ionic Liquids: an Alternative and Green Approach for Polymer Synthesis. Macromolecular Rapid Communications, Vol. 28, No. 4 (February 2007), pp. 456-464, ISSN: 1521-3927

Guo, Y.; Zhou, J.; Song, Y. \& Zhang, L. (2009). An Efficient and Environmentally Friendly Method for the Synthesis of Cellulose Carbammate by Microwave Heating. Macromolecular Rapid Communications, Vol. 30, No. 17 (September 2009), pp. 15041508, ISSN: 1521-3927

Hoogenboom, R.; Moore, B. C. \& Schubert, U. S. (2006). Synthesis of Star-Shaped Poly(عcaprolactone) via 'Click' Chemistry and 'Supramolecular Click' Chemistry. Chemical Communications, No. 38 (2006), pp. 4010-4012, ISSN: 1364-548X

Hui, A. Y.; Wang, G.; Lin, B. \& Chan, W. T. (2005). Microwave Plasma Treatment of Polymer Surface for Irreversible Sealing of Microfluidic Devices. Lab on a Chip, Vol. 5, No. 10 (October 2005), pp. 1173-1177, ISSN: 1473-0189

Jaja, S. \& Durance, T. D. (2008). Tailor-made Biopolymers Porous Scaffold Fabrication for Tissue Engineering: Application of Radiant Energy in the Form of Microwave under Vacuum. Bio-medical Materials and Engineering, Vol. 18, No. 6, pp. 357-366, ISSN: 0959-2989

Jing, S.; Peng, W.; Tong, Z. \& Baoxiu, Z. (2006). Microwave-Irradiated Ring-Opening Polymerization of D,L-Lactide Under Atmosphere. Journal of Applied Polymer Science, Vol. 100, No. 3 (may 2006), pp. 2244-2247, ISSN: 0021-8995

Karagöz, A. \& Dinçer, S. (2010). Microwave Assisted Synthesis of Poly(E-caprolactone)-blockpoly(ethylene gycol) and Poly(lactide)-block-poly(ethylene glycol). Macromolecular Symposia, Vol. 295, No. 1 (September 2010), pp. 131-137, ISSN: 1521-3900

Keki, S.; Bodnar, I.; Borda, J.; Deak, G. \& Zsuga, M. (2001). Fast Microwave-Mediated Bulk Polycondensation of D,L-Lactic Acid. Macromolecular Rapid Communications, Vol. 22, No. 13 (September 2001), pp. 1063-1065, ISSN: 1521-3927 
Kerep, P. \& Ritter, H. (2006). Influence of Microwave Irradiation on the Lipase-Catalyzed Ring Opening Polymerization of $\varepsilon$-Caprolactone. Macromolecular Rapid Communications, Vol. 27, No. 9 (May 2006), pp. 707-710, ISSN: 1521-3927

Koroskenyi, B. \& McCarthy S. (2002). Microwave-Assisted Solvent-Free or Aqueous-Based Synthesis of Biodegradable Polymers. Journal of Polymers and the Environment, Vol. 10, No. 3 (July 2002), pp. 93-104, ISSN: 1566-2543

Kremsner, J. M. \& Kappe, C. O. (2006). Silicon Carbide Passive Heating Elements in Microwave-Assisted Organic Synthesis. Journal of Organic Chemistry, Vol. 71, No. 12 (June 2006), pp. 4651-4658, ISSN: 0022-3263

Lei, H. C.; Wang, P. \& Yuan, W. B. (2009). Microwave-Assisted Synthesis of Poly(L-Lactic Acid) via Direct Melt Polycondensation using Solid Super Acids. Macromolecular Chemistry and Physics, Vol. 210, No. 23 (December 2009), pp. 2058-2062, ISSN: 15213935

Leonelli, C.; Veronesi, P. \& Grisoni, F. (2007). Numerical Simulation of an Industrial Microwave Assisted Filter Dryer: Criticality Assessment and Optimization. Journal of Microwave Power and Electromagnetic Energy, Vol. 41, No. 3 (October 2007), pp. 513, ISSN: 0832-7823

Leonelli, C. \& Mason, T. J. (2010). Microwave and Ultrasonic Processing: Now a Realistic Option for Industry. Chemical Engineering and Processing, Vol. 49, No. 9 (September 2010), pp. 885-900, ISSN: 0255-2701

Li, G.; Zhao, N.; Bai, W.; Chen, D. L. \& Xiong, C. D. (2010). Microwave-Assisted RingOpening Polymerization of Poly(glycolic acid-co-lactic acid) Copolymers. EPolymers, No. 051 (May 2010), pp. 1-6, ISSN: 1618-7229

Li, H.; Liao, L. \& Liu, L. (2007). Kinetic Investigation into the Non-Thermal Microwave Effect on the Ring Opening Polymerization of $\varepsilon$-Caprolactone. Macromolecular Rapid Communications, Vol. 28, No. 4 (February 2007), pp. 411-416, ISSN: 1521-3927

Li, Y.; Wang, X. L.; Yang, K. K. \& Wang, Y. Z. (2006). A Rapid Synthesis of Poly(pdioxanone) by Ring Opening Polymerization under Microwave Irradiation. Polymer Bulletin, Vol. 57, No. 6 (October 2006), pp. 873-880, ISSN: 0170-0839

Liao, L.; Liu, L. \& Zhang, C. (2006). Microwave-Assisted Ring Opening Polymerization of $\varepsilon-$ Caprolactone in the Presence of Ionic Liquid. Macromolecular Rapid Communications, Vol. 27, No. 24 (December 2006), pp. 2060-2064, ISSN: 1521-3927

Liao, L.; Zhang, C. \& Gong, S. (2008). Preparation of Poly(trimethylene carbonate)-blockpoly(ethylene glycol)-block-poly(trimethylen carbonate) Triblock Copolymers under Microwave Irradiation. Reactive and Functional Polymers, Vol. 68, No. 3 (March 2008), pp. 751-758, ISSN: 1381-5148

Lidström, P.; Tierney, J.; Wathey, B. \& Westman, J. (2001). Microwave Organic Synthesis - a Review. Tetrahedron, Vol. 57, No. 45 (November 2001), pp. 9225-9283, ISSN: 00404020

Liu, F.; Qian, X.; Wu, X.; Guo, C.; Ley, Y. \& Zhang, J. (2010). The Response of Carbon Black Filled High-density Polyethylene to Microwave Processing. Journal of Materials Processing Technology, Vol. 210, No. 14 (November 2010), pp. 1991-1996, ISSN: 09240136 
Liu, L.; Liao, L. Q.; Zhang, C.; He, F. \& Zhuo, R. X. (2001). Microwave-Assisted Polycondensation of L-2-hydroxy-3-phenylpropanoic Acid. Chinese Chemical Letters, Vol. 12, No. 9 (September 2001), pp. 761-762, ISSN: 1001-8417

Liu, L.; Li, Y.; Fang, Y. \& Chen, L. (2005). Microwave-Assisted Graft Copolymerization of $\varepsilon-$ Caprolactone onto Chitosan via the Phtaloyl Protection Method. Carbohydrate Polymers, Vol. 60, No. 3 (May 2005), pp. 351-356, ISSN: 0144-8617

Liu, P.; Su, Z. (2005). Thermal Stabilities of Polystyrene/Silica Hybrid Nanocomposites via Microwave-assisted In-situ Polymerization. Materials Chemistry and Physics, Vol. 94, No. 3 (December 2005), pp. 412-415, ISSN: 0254-0584

Makino, A. \& Kobayashi, S. (2010). Chemistry of 2-Oxazolines: a Crossing of Cationic RingOpening Polymerization and Enzymatic Ring-Opening Polyaddition. Journal of Polymer Science - Part A: Polymer Chemistry, Vol. 48, No. 6 (March 2010), pp. 12511270, ISSN: 1099-0518

Mishra, S.; Mukul, A.; Sen, G. \& Jha, U. (2011). Microwave Assisted Synthesis of Polyacrylamide Grafted Starch (St-g-PAM) and its Applicability as Flocculant for Water Treatment. International Journal of Biological Macromolecules, Vol. 48, No. 1 (January 2011), pp. 106-111, ISSN: 0141-8130

Mishra, A.; Clark, J. H.; Vij, A. \& Daswal, S. (2008). Synthesis of Graft Copolymers of Xyloglucan and Acrylonitrile. Polymers for Advanced Technologies, Vol. 19, No. 2 (February 2008), pp. 99-104, ISSN: 1042-7147

Moseley, J. D. \& Woodman E. K. (2008). Scaling-Out Pharmaceutical Reactions in an Automated Stop-Flow Microwave Reactor. Organic Processes Research $\mathcal{E}$ Development, Vol. 12, No. 5 (September 2008), pp. 967-981, ISSN: 1083-6160

Moseley, J. D. \& Kappe, C. O. (2011). A Critical Assessment of the Greenness and Energy Efficiency of Microwave-assisted Organic Synthesis. Green Chemistry, Advance Article, ISSN: 1463-9270

Nikolic, L.; Ristic, I,; Adnadjevich, B.; Nikolic, V.; Jovanovich, J. \& Stankovich, M. (2010). Novel Microwave-Assisted Synthesis of Poly(D,L-Lactide): the Influence of Monomer/Initiatior Ratio on the Product Properties. Sensors, Vol. 10, No. 5 (May 2010), pp. 5063-5073, ISSN: 1424-8220

Nadagouda, M. N. \& Varma, R. S. (2007). Preparation of Novel Metallic and Bimetallic Cross-Linked Poly(vinyl alcohol) Nanocomposites under Microwave Irradiation. Macromolecular Rapid Communications, Vol. 28, No. 4 (February 2007), pp. 465-472, ISSN: 1521-3927

Nagahata, R.; Sano, D.; Suzuki, H. \& Takeuchi, K. (2007). Microwave-Assisted Single-Step Synthesis of Poly(lactic acid) by Direct Polycondensation of Lactic Acid. Macromolecular Rapid Communications, Vol. 28, No. 4 (February 2007), pp. 437-442, ISSN: 1521-3927

Nuchter, M.; Ondruschka, B.; Bonrath, W. \& Gum, A. (2004). Microwave Assisted Synthesis - a Critical Technology Overview. Green Chemistry, Vol. 6, No. 3 (2004), pp. 128-141, ISSN: 1463-9270

Perreux, L. \& Loupy, A. (2001). A Tentative Rationalization of Microwave Effects in Organic Synthesis According to the Reaction Medium, and Mechanistic Considerations. Tetrahedron, Vol. 57, No. 45 (November 2001), pp. 9199-9223, ISSN: 0040-4020 
Polshettiwar, V.; Nadagouda, M. N. \& Varma, R. S. (2009). Microwave-Assisted Chemistry: a Rapid and Sustainable Route to Synthesis of Organics and Nanomaterials. Australian Journal of Chemistry, Vol. 61, No. 1 (January 2009), pp. 16-26, ISSN: 00049425

Prasad, K.; Meena, R. \& Siddhanta, A. K. (2006). Microwave-Induced Rapid One-Pot Synthesis of K-Carrageennan-g-PMMA Copolymer by Potassium Persulphate Initiating System. Journal of Applied Polymer Chemistry, Vol. 101, No. 1 (July 2006), pp. 161-166, ISSN: 1097-4628

Razzaq, T. \& Kappe, C. O. (2008). On the Energy Efficiency of Microwave-Assisted Organic Reactions. ChemSusChem, Vol. 1, No. 1-2 (February 2008), pp. 123-132, ISSN: 1864$564 X$

Riaz, U.; Ashraft, S. M. \& Sharma, H. O. (2011). Mechanical, Morphological and Biodegradation Studies of Microwave Processed Nanostructured Blends of Some Bio-based Oil Epoxies with Poly(vinyl alcohol). Polymer Degradation and Stability, Vol.96, No. 1 (January 2011), pp. 33-42, ISSN: 0141-3910

Satgé, C.; Verneuil, B.; Branland, P.; Granet, R.; Krausz, P.; Rozier, P. \& Petit, C. (2002). Rapid Homogeneous Esterification of Cellulose Induced by Microwave Irradiation. Carbohydrate Polymers, Vol. 49, No. 3 (August 2002), pp. 373-376, ISSN: 0144-8617

Sahu, A.; Goswami, P. \& Bora, U. (2009). Microwave Mediated Rapid Synthesis of Chitosan. Journal of Material Science: Materials in Medicine, Vol. 20, No. 1 (January 2009), pp. 171-175, ISSN: 1573-4838

Sharma, A. K. \& Mishra, A. K. (2010). Microwave Induced $\beta$-cyclodextrin Modification of Chitosan for Lead Sorption. International Journal of Biological Macromolecules, Vol. 47, No. 3 (October 2010), pp. 410-419, ISSN: 0141-8130

Singh, V.; Singh, S. K. \& Maurya, S. (2010). Microwave Induced Poly(acrylic acid) Modification of Cassia Javanica Seed Gum for Efficient $\mathrm{Hg}(\mathrm{II})$ Removal from Solution. Chemical Engineering Journal, Vol. 160, No. 1 (May 2010), pp. 129-137, ISSN: 1385-8947

Singh, V.; Sharma, A. K. \& Maurya, S. (2009). Efficient Cadmium (II) Removal from Aqueous Solution Using Microwave Synthesized Guar Gum-GraftPoly(ethylacrylate). Industrial \& Engineering Chemistry Research, Vol. 48, No. 10 (May 2009), pp. 4688-4696, ISSN: 0888-5885

Singh, V.; Tiwari, A.; Tripathi, D. N. \& Sanghi, R. (2004). Microwave Assisted Synthesis of Guar-g-polyacrylamide. Carbohydrate Polymers, Vol. 58, No. 1 (October 2004), pp. 16, ISSN: 0144-8617

Singh, V.; Tiwari, A.; Tripathi, D. N. \& Sanghi, R. (2004). Grafting of Polyacrylonitrile onto Guar Gum under Microwave Irradiation. Journal of Applied Polymer Science, Vol. 92, No. 3 (May 2004), pp. 1569-1575, ISSN: 0021-8995

Sinwell, S.; Schmidt, A. M. \& Ritter, H. (2006). Direct Synthesis of (Meth-)acrylate Poly(عcaprolactone) Macromonomers. Journal of Macromolecular Science - Part A: Pure and Applied Chemistry, Vol. 43, No. 3 (March 2006), pp. 469-476, ISSN: 1520-5738

Sivalingam, G.; Agarwal, N. \& Madras, G. (2004). Kinetics of Microwave-Assisted Polymerization of $\varepsilon$-Caprolactone. Journal of Applied Polymer Science, Vol. 91, No. 3 (February 2004), pp. 1450-1456, ISSN: 0021-8995 
Strauss, C. R. \& Trainor, R. W. (1995). Developments in Microwave-assisted Organic Chemistry. Australian Journal of Chemistry, Vol. 48, No. 10 (October 1995), pp. 16651692, ISSN: 0004-9425

Tan, Y.; Cai, S.; Liao, L.; Wang, Q. \& Liu, L. (2009). Microwave-Assisted Ring-Opening Polymerization of $\varepsilon$-Caprolactone in Presence of Hydrogen Phosphonates. Polymer Journal, Vol. 41, No. 10 (October 2009), pp. 849-854, ISSN: 0032-3896

Thostenson, E. T. \& Chou, T. W. (1999). Microwave Processing: Fundamentals and Applications. Composites - Part A: Applied Science and Manifacturing, Vol. 30, No. 9 (September 1999), pp. 1055-1071, ISSN: 1359-835X

Tong, Z.; Peng, W.; Zhiqian, Z. \& Baoxiu Z. (2004). Microwave Irradiation Copolymerization of Superabsorbents from Cornstarch and Sodium Acrylate. Journal of Applied Polymer Science, Vol. 95, No. 2 (January 2004), pp. 264-269, ISSN: 0021-8995

Torres, F. G.; Boccaccini, A. R. \& Troncoso, O. P. (2007). Microwave Processing of Starchbased Porous Structures for Tissue Engineering Scaffolds. Journal of Applied Polymer Science, Vol. 103, No. 2 (January 2007), pp. 1332-1339, ISSN: 0021-8995

Velmathi, S.; Nagahata, R.; Sugiyama, J. \& Takeuchi, K. (2005). A Rapid, Eco-Friendly Synthesis of Poly(butylene succinate) by a Direct Polyesterification under Microwave Irradiation. Macromolecular Rapid Communications, Vol. 26, No. 14 (July 2005), pp. 1163-1167, ISSN: 1521-3927

Vogel, B. M.; Mallapragada, S. K. \& Narasimhan, B. (2003). Rapid Synthesis of Polyanhydrides by Microwave Polymerization. Macromolecular Rapid Communications, Vol. 25, No. 1 (January 2004), pp. 330-333, ISSN: 1521-3927

Wan, Z.; Xiong, Z.; Ren, H.; Huang, Y.; Liu, H.; Xiong, H.; Wu, Y. \& Han, J. (2011). Graft Copolymerization of Methyl Methacrylate onto Bamboo Cellulose under Microwave Irradiation. Carbohydrate Polymers, Vol. 83, No. 1 (January 2011), pp. 264-269, ISSN: 0144-8617

Waugh, M. R. \& Parkin, I. P. (2010). Enhanced Solubility and Covalent Solubilization of Single Walled Carbon Nanotubes via Atmospheric Pressure Microwave Reflux and the Subsequent Spray Coating of Transparent Conducting Thin Films. Current Nanoscience, Vol. 6, No. 3 (June 2010), pp. 232-242, ISSN: 1573-4137

Wiesbrock, F.; Hoogenboom, R. Abeln, C. H. \& Schubert, U. S. (2004). Single-Mode Microwave Ovens as New Reaction Devices: Accelerating the Living Polymerization of 2-Ethyl-2-oxazoline. Macromolecular Rapid Communications, Vol. 25, No. 22 (November 2004), pp. 1895-1899, ISSN: 1521-3927

Wu, C. Y. \& Benatar, A. (1997). Microwave Welding of High Density Polyethylene Using Intrinsically Conductive Polyaniline. Polymer Engineering and Science, Vol. 37, No. 4 (April 2007), pp. 738-743, ISSN: 1548-2634

Xu, Q.; Zhang, C.; Cai, S.; Zhu, P. \& Liu, L. (2010). Large-Scale Microwave-Assisted Ring Opening Polymerization of $\varepsilon$-Caprolactone. Journal of Industrial and Engineering Chemistry, Vol. 16, No. 5 (September 2010), pp. 872-875, ISSN: 1226-086X

Yarlagadda, P. K. D. V. \& Chai, T. C. (1998). An Investigation into Welding of Engineering Thermoplastics Using Focused Microwave Energy. Journal of Materials Processing Technology, Vol. 74, No. 1-3 (February 1998), pp. 199-212, ISSN: 0924-0136 
Yu, Z. J.; Liu, L. J. \& Zhuo, R. X. (2003). Microwave-Improved Polymerization of $\varepsilon$ Caprolactone Initiated by Carboxylic Acids. Journal of Polymer Science - Part A: Polymer Chemistry, Vol. 41, No. 1 (January 2003); pp. 13-21, ISSN: 1099-0518

Yu, Z. J. \& Liu, L. J. (2004). Effect of Microwave Energy on Chain Propagation of Poly( $\varepsilon-$ caprolactone) in Benzoic Acid Initiated Ring Opening Polymerization of $\varepsilon$ Caprolactone. European Polymer Journal, Vol. 40, No. 9 (September 2004), pp. 22132220, ISSN: 0014-3057

Yu, Z. J. \& Liu, L. J. (2007). Biodegradable Poly(vinyl alcohol)-graft-poly(e-caprlactone) Comb-like Polyesters: Microwave Synthesis and its Characterization. Journal of Applied Polymer Science, Vol. 104, No. 6 (June 2007), pp. 3973-3979, ISSN: 0021-8995

Zhang, C.; Liao, L. \& Liu, L. (2004). Rapid Ring-Opening Polymerization of D,L-Lactide by microwaves. Macromolecular Rapid Communications, Vol. 25, No. 15 (August 2004), pp. 1402-1405, ISSN: 1521-3927

Zhang, C.; Liao, L. \& Gong, S. (2007). Microwave-Assisted Synthesis of PLLA-PEG-PLLA Triblock Copolymers. Macromolecular Rapid Communications, Vol. 28, No. 4 (February 2007), pp. 422-427, ISSN: 1521-3927

Zhang, Y.; Wang, P.; Han, N. \& Lei, H. (2009). Synthesis of Poly(D,L-Lactide) under Continuous Microwave Irradiation. Shiyou Huagong/Petrochemical Technology, Vol. 38, No. 8 (August 2009), pp. 861-865, ISSN: 1000-8144

Zhou, J.; Shi, C.; Mei, B.; Yuan, R. \& Fu, Z. (2003). Research on the Technology and Mechanical Properties of the Microwave Processing of Polymers. Journal of Materials Processing Technology, Vol. 137, No. 1-3 (June 2003), pp. 156-158, ISSN: 0924-0136

Zhu, X.; Zhou, N.; He, X.; Cheng, Z. \& Lu, J. (2003). Atom Transfert Radical Bulk Polymerization of Methyl Methacrylate under Microwave Irradiation. Journal of Applied Polymer Science, Vol. 88, No. 7 (May 2003), pp. 1787-1793, ISSN: 0021-8995 


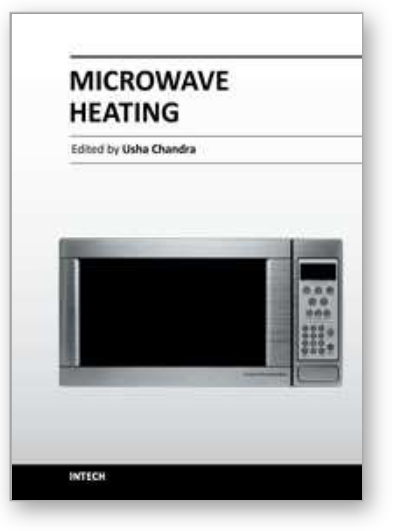

\author{
Microwave Heating \\ Edited by Dr. Usha Chandra
}

ISBN 978-953-307-573-0

Hard cover, 370 pages

Publisher InTech

Published online 27, July, 2011

Published in print edition July, 2011

The Microwave heating has not only revolutionized the food industry but also has extended its wings widely towards its multidimensional applications. Thus it has opened new vistas of potential research in science and technology. The book is compiled into Seventeen Chapters highlighting different aspects varying from epistemological discussion to applicability of conceptual constructs. The inclusion of discussion on the avenues in the field of Chemistry, Health \& Environment, Medical Sciences and Technology makes it an exquisite work for the aspirant Researchers. As the text book for the beginners, it is designed fundamentally to be a reference monograph to the experts providing a passage for future research. The plethora of literatures are available on Microwave Applications but they seldom direct their readers to concentrate on the key aspects behind the success in microwave applications in different fields. Here is the attempt to fill up the gap with this book.

\title{
How to reference
}

In order to correctly reference this scholarly work, feel free to copy and paste the following:

Marco Frediani, Guido Giachi, Luca Rosi and Piero Frediani (2011). Synthesis and processing of biodegradable and bio-based polymers by microwave irradiation, Microwave Heating, Dr. Usha Chandra (Ed.), ISBN: 978-953-307-573-0, InTech, Available from: http://www.intechopen.com/books/microwaveheating/synthesis-and-processing-of-biodegradable-and-bio-based-polymers-by-microwave-irradiation

\section{INTECH}

open science | open minds

\author{
InTech Europe \\ University Campus STeP Ri \\ Slavka Krautzeka 83/A \\ 51000 Rijeka, Croatia \\ Phone: +385 (51) 770447 \\ Fax: +385 (51) 686166 \\ www.intechopen.com
}

\author{
InTech China \\ Unit 405, Office Block, Hotel Equatorial Shanghai \\ No.65, Yan An Road (West), Shanghai, 200040, China \\ 中国上海市延安西路65号上海国际贵都大饭店办公楼 405 单元 \\ Phone: +86-21-62489820 \\ Fax: +86-21-62489821
}


(C) 2011 The Author(s). Licensee IntechOpen. This chapter is distributed under the terms of the Creative Commons Attribution-NonCommercialShareAlike-3.0 License, which permits use, distribution and reproduction for non-commercial purposes, provided the original is properly cited and derivative works building on this content are distributed under the same license. 